\title{
Simulation of a sachet water processing plant using an analogous electrical model
}

\author{
Ani Vincent Anayochukwu \\ Department of Electronic Engineering, University of Nigeria, Nsukka. Enugu State, Nigeria.
}

Accepted 25 June, 2013

\begin{abstract}
This paper presents an electrical model for studying the process behaviour of a sachet water production plant. In this model, the mechanical components of the plant such as the connecting pipes, the water tanks and the water filter were represented by resistors, capacitors and an inductor, respectively. A state equation was developed as a mathematical model of the electrical circuit. In this equation, resistors, capacitors and inductor representing the restriction of the pipes, the capacity of the tanks and the filtration of the filter respectively, were used as variable parameters to generate the state variables of the state equation. This mathematical model was used to simulate the effects of varying the electrical parameters $(R, C$, and $L)$ on the state variables ( $v$ and $i$ ) representing the restriction of the connecting pipes, the water levels $(h)$ in the water tanks and the filtration of the water filter, respectively. Insight into the response curves will indeed form the basis for studying the process control of the sachet water processing plant.
\end{abstract}

Key words: Mathematical model, analogous system, state equation, control, modeling, simulation

\section{INTRODUCTION}

Over the years, man has constantly searched for reliable methods of controlling things around him to suit his purpose. The successful operation of a system under changing conditions often requires a control system. The flow of water in a Production Plant was previously monitored by having an operator take a pressure reading in the treatment plant once or twice a day. Obviously, this daily routine was wasteful and hardly accurate. It was impossible to maintain a stable flow even with nearly continuous operator intervention. The correct amount of water needed to sachet was very difficult, if not impossible, to ascertain from a pressure reading and thus overshooting of desired flow was common.

Sachet water plants without process control are likely to experience problems, such as the water level in the filter cells in the tanks tend to fluctuate widely and create the potential for partial drainage, overflow, and potential initial turbidity breakthrough at the beginning of the filtration cycles thereby causing most of the products not to fill properly.

The necessary condition for achieving efficient process control resides in a thorough understanding of the dynamics of water flow through the plant. If the internal conditions would be predictable through modeling and simulation, we could design a process control that would operate continuously to supply properly filled water sachets at a predetermined sachet plant. Therefore, the mathematical model representing the dynamic behaviour of the process is developed and the system variables expressed in state variable form. In this way, the entire analysis is fashioned in such a way that it is amenable to computer simulation.

In this paper, an Analogous Electrical model for sachet water processing plant is developed. A 
step-by-step analogous model strategy as proposed by Ani (2007) is adopted: the development of an electrical model of the sachet water production plant, computer simulation of the electrical model and the analysis of the results of the simulation time. This paper spotlights the effects of process control modeling on the treatment of simple water.

\section{Water}

Water is one of the prime natural resources, an essential commodity for the living systems that constitute the biosphere (Casey, 2006); unique in its properties - the only substance to exist in all three phases, solid, liquid and gaseous, within the temperature range of the natural environment, continually renewed by the natural hydrological cycle of evaporation, vapour transportation and precipitation. Water conservation opportunities arise in increased efficiency through improvements in flow rates, pressure, temperature, chemistry, filtration or timing (Le Chevallier and Kwok-Keung, 2004). Metering both inflow and outflow from the system provides the operator information to determine if the system is meeting design efficiencies. Process control is often an area where increased efficiency can be obtained. Many operations can also increase efficiency by recirculating water or by filtering contaminants and reclaiming water for reuse internally. Thus the engineering associated with water resources management and use is multifaceted (Ani, 2013b). This treatise deals with the technologies used to control the treatment process and its related use in industrial manufactures. It deals with the range of treatment processes used in the production of drinking and other high quality water. In general, the presentation of the subject matter proceeds sequentially from basic principles through analytical/experimental methods to the development of process design methodologies. Processes are treated as unit operations, emphasizing those process fundamentals which can be applied to all process applications.

\section{Physical components describing the sachet water plant}

The basic physical parameters used in describing the properties of the sachet water production plant are: Pipe (restriction), tank (capacity) and filter (water filteration).

These parameters from the basis of a conceptual design were used in constructing the passive resistance, capacitance and inductance electrical network for the analog model. To accurately stimulate the process, these parameters should be known at all locations throughout the area being modeled. The general boundary of the model is the demarcation between where recharge enters and discharge leaves the plant. The boundary was chosen so that cause-and-effect relations outside the model area would not affect the process data of the sachet water production system which are useful in preparing an analog model. The better defined the process is, the more accurate the working model (Hardt, 1971). Figure 1 shows the physical setup with all the various regulating devices.

\section{ANALOGOUS SYSTEMS}

Analog models are physical models in a different physical system used to model the original model. An analog model can be the use of electrical circuits to represent mechanical systems such as automobile suspensions. An example of an analog model is a direct analog model where series mechanical elements are replaced by analogous series electrical elements and parallel mechanical elements are replaced by equivalent electrical elements in parallel (Ani, 2013a; Hardt, 1971). The use of electric analog model in fluid flow is possible because of the mathematical similarity between the flow of electricity in conducting materials and the flow of fluid in porous media (Walton and Prickett, 1963; Pattern, 1965). Electric analog methods are now regarded as one of the powerful computing tools available to the hydrologist. Direct simulation of the hydrologic system by electrical methods simplifies the computational process. Once the analog model is verified through the use of field data, all electrical phenomena observed on the model can be directly related to hydrologic factors. Any theoretical set of water flow conditions, including alternative solutions, can be modeled, and the effects observed (Hardt, 1971).

The electrical conductivity of the resistors is proportional to the hydraulic conductivity of the plant, and the electrical capacitance is directly related to the storage coefficient of the plant. A resistor impedes the flow of electricity in the same way as the piping materials impede the flow of water through the plant; likewise, capacitor stores electricity in a manner similar to the way water is stored in a tank. If such a model is quantified, the electrical units of potential, charge, current, and model time correspond to the hydraulic units of head, volume, flow rate, and real time. The concept of analogous system is a very useful and powerful technique for system modeling (Ani, 2013a; Dorf and Bishop, 1998).

To develop fully an analog model requires detailed analysis of the process parameters. The flow system 


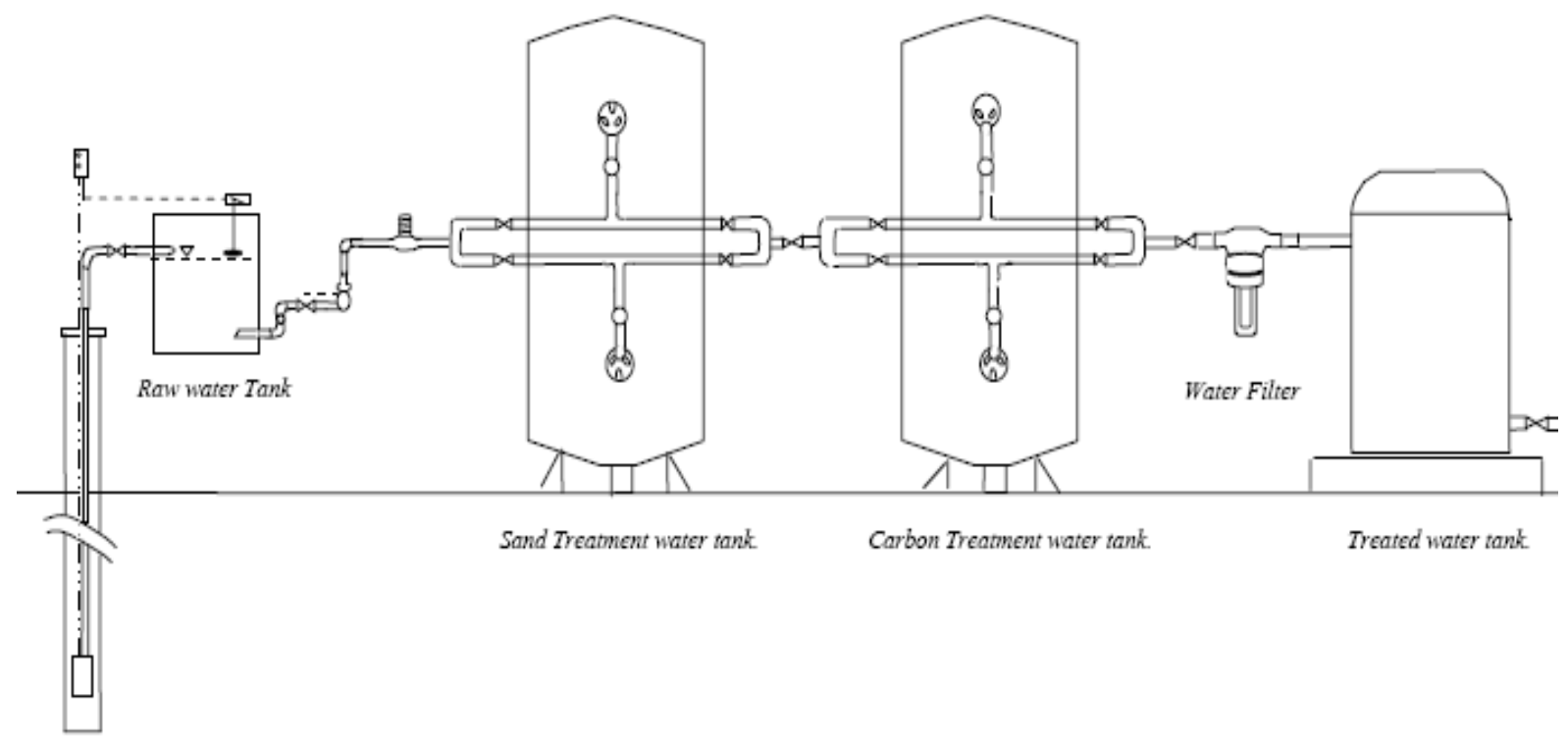

Submersible Pump

Figure 1. Flow sheet of a water treatment plant (Ani, 2007).

under equilibrium or steady-state conditions (before development) is described by a form of law of conservation of mass (fluid flow continuity).

$$
\dot{m}=q_{i}-q_{o}
$$

This simply states that the time rate of change $\dot{m}$ of mass in a container must equal the total mass inflow rate minus the total outflow rate. The quantity of water moving into the plant (recharge) is about equal to the quantity of water moving out of the plant (discharge). Water levels in the plant are a function of the magnitude of inflow and outflow and the characteristics of the materials through which the water is moving.

In liquid flow system, the differential equation describing liquid flow is derived by law of conservation of mass.

$C \frac{d h}{d t}=\frac{h}{R}$

Where:

$C=$ storage coefficient (dimensionless)

$\frac{d h}{d t}=$ change in water level with time, in metre per seconds.

$h=$ water level, in meters

$R=$ restriction in piping $t=$ time, in hours

The equivalent equation for field in electricity is derived by Kirchhoff's voltage and current laws as:

$C \frac{d v}{d t}=\frac{v}{R}$

Where:

$C=$ electrical capacitance, in farads

$\frac{d v}{d t}=$ change in voltage with time

$t=$ time, in seconds

$R=$ electrical resistance, in ohms

$v=$ electrical potential, in volts

The similarity between these two equations indicates that the cause-and-effect response in a hydrologic system can be duplicated in an electrical system, provided the two are dimensionally equivalent (Hardt, 1971). Mathematically, a solution to the response of developed plant requires use of equations that are too complex for ordinary solution. However, an electric analog model can be constructed that closely approximates the actual flow system because the flow of fluid through porous media is analogous to the flow of current through conducting material. A model that is quantitatively proportional to the liquid flow system can be built by selecting proper electrical components.

Comparison of these two equations show that the behaviour of the two systems is determined by the 
same basic differential equation. The systems are analogous and there is a one-one correspondence between the elements of the two systems. The analogy is very close. The effect of variations in L, C and $R$ on the water-levels in the hydraulic system can thus be determined by simply observing the effect on the voltages in the electric circuit of variation in $\mathrm{L}, \mathrm{C}$ and $\mathrm{R}$. The voltage across the capacitor and the current in the circuit vary in the same way as the water-Level and velocity of the mass (Ord-Smith and Stephenson, 1975). In complex water-flow systems, it is impractical to measure all these parameters in great detail or with high accuracy. If, however, they are known approximately, initial tests can be made with an analog model. Usually model response on the first few trails bears little resemblance to actual water-level changes.

Through evaluation of model response and reconsideration of the original plant parameters, the model design is revised until the water-level change computed by the model agrees with observed changes (Hardt, 1971). However, electrical analogies have the advantage that they can be easily set up in the laboratory. A change in a particular parameter can be accomplished very easily in the electric circuit to determine its overall effects and the electric circuit can be approximately adjusted for the desired response.

Afterwards, the parameters in the liquid level system can be adjusted by an analogous amount to obtain the same desired response (Schwedes, 1995).

\section{Volumetric flow rate as analogous to current}

Volumetric flow rate $Q$ is defined as the quantity of fluid passing a given area per unit time and current $i$ is defined as the rate of flow of charge across a given area, often the cross-sectional area of a wire.

Mathematically:

$Q=\frac{d V}{d t}$

$i=\frac{d Q}{d t}$

When two parts or elements of a fluid system are connected by a section of pipe, the principle of conservation of mass states that the amount of fluid leaving element A must enter element B. This principle also requires that the net flow rate of mass into any fluid system must equal the rate of increase of mass inside the system.

As the fluid is incompressible, the preceding statement also applies to volume flow rate and fluid volume.
In electrical system, when two elements are connected together, the principle of conservation of electric charge requires that the net charge-leaving element $A$ must enter element $B$. This principle also requires that the charge entering an element minus the charge leaving the element must equal the change of net charge stored within the element.

\section{Analogous components and variables}

Analogous systems are physical systems that are identical; each can be replaced by the other system by deduction of dynamic behaviour of one of these systems from the dynamic behaviour of the other. Just like the deduction of electrical system behaviour from the hydraulic system behaviour.

The model generally starts as an analytical model, that is, a set of differential equations.

Using principle of analogy, which states that two different physical systems can be described by the same mathematical model, these equations are converted into an electrical circuit. This permits a generalization of ideas specific to a particular field in order that a broader understanding of a variety of apparently unrelated situations can be achieved.

The electrical circuit analogy is a force (flow) to current analogy as outlined in Tables 1 and 2 .

The analogous components and variables are thus:

$i_{i}=Q_{i}$ (Input current; water flow into the process).

$i_{o}=Q_{o}$ (Output current; water flow from the process).

$C_{1}=$ (Capacitance of capacitor 1 ; Capacity of tank 1 (sand treatment tank)).

$C_{2}=$ (Capacitance of capacitor 2; Capacity of tank 2 (carbon treatment tank)).

$L=$ (Inductance of the inductor; filteration of the filter).

$C_{3}=$ (Capacitance of capacitor 3 ; Capacity of tank 3 (Treated water tank)).

$v_{c 1}=h_{1}$ (voltage across capacitor 1 ; water level of tank 1).

$v_{c 2}=h_{2}$ (voltage across capacitor 2; water level of tank 2).

$v_{c 3}=h_{3}$ (voltage across capacitor 3; water level of tank 3).

$i_{1}=Q_{1}$ (flow of current through the inductor; rate of water flow through the filter).

$R_{1}=$ (Resistance of the resistor 1 ; Restriction of pipe 1).

$R_{2}=($ Resistance of the resistor $2 ;$ Restriction of pipe 2). 
Table 1. Describing differential equations for ideal elements of an analog system (Pattern, 1965; Dorf and Bishop, 1998).

\begin{tabular}{llc}
\hline Types of element & Physical element & Describing equation \\
\hline Inductive storage & Electrical Inductance $L$ & $v=L \frac{d i}{d t}$ \\
\hline & Fluid Inertia $I$ & $p=I \frac{d Q}{d t}$ \\
\hline Capacitive storage & Electrical Capacitance $C$ & $i=C \frac{d v}{d t}$ \\
\hline & Fluid Capacitance $C_{f}$ & $Q=C_{f} \frac{d p}{d t}$ \\
\hline Energy dissipator & Electrical Resistance $R$ & $i=\frac{1}{R} v$ \\
\hline & Fluid Resistance $R_{f}$ & $Q=\frac{1}{R_{f}} p$ \\
\hline
\end{tabular}

Table 2. Through-and-across-variable for an analog system (Pattern, 1965; Dorf and Bishop, 1998).

\begin{tabular}{llll}
\hline System & Variable through element & Variable across element & Integrated through variable \\
\hline Electrical & Current, $i$ & Voltage, $v$ & Charge, $q$ \\
Liquid-level & Liquid flow rate, $Q$ & water level, $h$ & Liquid flow, $q$ \\
\hline
\end{tabular}

$R_{3}=$ (Resistance of the resistor 3; Restriction of pipe 3).

The Liquid - Levels, $h_{1}, h_{2}$, and $h_{3}$ of the flow system are directly analogous to the node voltages $v_{1}, v_{2}$ and $v_{3}$ of the electrical circuit. Therefore, an electrical circuit is analogous to fluid flow system/plant, implying that the process control of a sachet water plant can be model by means of an electrical model.

Figure 1 shows the physical arrangement of how the system components function and it forms the basis for an analytical study. The electrical circuit representation of the system is shown in Figure 3.

Using the method of analogy for which Kirchhoff's voltage and current laws are utilized, we obtain the state equation. The network has four energy storage elements: three capacitors $C_{1}, C_{2}, C_{3}$, and an inductor $L$, and this network are specified by the voltage across the capacitors and current through the inductor. Since there are potential differences across the capacitors as well as current through the inductor, this electrical picture leads to ordinary differential equations. History of the network is completely specified by the voltages across the capacitors and current through the inductor at $t=0$ (Nise, 2003). This involves the identification of individual system components as well as identification and idealization of their interconnection.

Interconnection of the elements imposes constraints on the variation of system variables, and the convenient way of specifying these constraints is by a mathematical statement of the way in which the various through-variables are related and the way in which the various across-variables are related. This package of equations is a complete mathematical description of the system (Shearer et al., 1971). The essence of the model is to provide the medium in which the controlled process can be analyzed without practically meddling with the operations of the real system.

\section{MATHEMATICAL MODEL DEVELOPMENT}

In order to develop the mathematical model of the system in Figure 1, the following assumptions are made (Ani, 2007):

1. Pressure differences at various stages of the process (water flow), which implies an adoption of a positive-flow direction through the Interconnected elements.

2. The input flow is equal to output flow if and only if the water level at each stage (capacitance) in the plant remains constant, which agrees with the law of conservation of mass. 
3. Fluid's density remains constant despite changes in the fluid pressure (Model fluid behaviour as incompressible).

4. Laminar flow exists (the model for the tank height is linear).

5. The walls of the treatment tank and the reservoir are rigid.

Based on the assumption that the inflow minus outflow during the small time interval $d t$ is equal to the additional amount stored in the tank, we see that

$c d h=\left(q_{i}-q_{0}\right) d t$ or $c \frac{d h}{d t}=q_{i}-q_{0}$

Where:

$\frac{d h}{d t}$ is the dependent variable reflecting the system's behaviour, $C$ is a parameter representing a property of the system, and $q_{i}-q_{o}$ represent the independent variable along which the system's behaviour is being determined.

From the definition of resistance, the relationship between $q_{0}$ and $h$ is given by

$$
q_{0}=\frac{h}{R}
$$

This is a model that relates water flow rate to the height of water in each tank in the plant. For each tank a flow continuity equation can be written in which the rate of change of fluid volume is equated to the rate of inflow of fluid.

The model generally starts as an analytical model, which is a set of differential equations. Using principle of analogy, which states that two different physical systems can be described by the same mathematical model, these equations are converted into an Electrical circuit. This permits a generalization of ideas specific to a particular field in order that a broader understanding of a variety of apparently unrelated situations can be achieved.

The development of these two models (Fluid and Electrical) follows a very similar process. Their respective relations in both cases enable one to relate the two-coupled sets of physical variables: Hydraulic and Electrical.

An electrical model of process control of a sachet water plant conveys a mental picture of the process control's actual behaviour in a variety of circumstances.

The developed mathematical model of process control of sachet water based on the equivalent circuit shown in Figure 2 is stated below:

From the circuit diagram, selection of the state variables is thus:

$x_{1}=v_{c 1}=h_{1}$ (voltage across the capacitor $1\left(\mathrm{C}_{1}\right)$; water level of tank $\left.1\left(h_{1}\right)\right)$.

$x_{2}=v_{c 2}=h_{2}$ (voltage across the capacitor $2\left(\mathrm{C}_{2}\right)$; water level of tank $\left.2\left(\mathrm{~h}_{2}\right)\right)$.

$x_{3}=i_{1}=Q_{1}$ (current through the inductor and rate of water flow through the filter).

$x_{4}=v_{c 3}=h_{3}$ (voltage across the capacitor $3\left(\mathrm{C}_{3}\right)$; water level of tank $\left.3\left(h_{3}\right)\right)$.

Where $v_{c}$ is the state variable representing voltage capacitor across each and $h$ is an equivalent state variable representing the height of water in the tank.

The system of differential equations which govern and describes the dynamic behaviour of the model under transient conditions is presented (Ani, 2013b).

$$
\begin{aligned}
& \mathrm{C}_{1} \frac{d\left(v_{c 1}\right)}{d t}=i-\left(\frac{v_{c 1}-v_{c 2}}{R_{1}}\right) \\
& C_{2} \frac{d\left(v_{c 2}\right)}{d t}=\left(\frac{v_{c 1}-v_{c 2}}{R_{1}}\right)-i_{1} \\
& L \frac{d\left(i_{1}\right)}{d t}=\frac{L}{R_{2}} \frac{d\left(v_{c 2}\right)}{d t}+v_{c 2}-v_{c 3} \\
& \mathrm{C}_{3} \frac{d\left(v_{c 3}\right)}{d t}=\frac{L}{R_{2}} \frac{d\left(v_{c 2}\right)}{d t}+v_{c 2}-\frac{v_{c 3}}{R_{3}}
\end{aligned}
$$

Rearranging the equations:

From Equation (8)

$$
\begin{aligned}
& C_{1} \frac{d\left(v_{c 1}\right)}{d t}=i-\left(\frac{v_{c 1}-v_{c 2}}{R_{1}}\right) \\
& C_{1} \frac{d\left(v_{c 1}\right)}{d t}=i-\frac{\left(v_{c 1}-v_{c 2}\right)}{R_{1}} \\
& C_{1} \frac{d\left(v_{c 1}\right)}{d t}=\frac{i R_{1}-v_{c 1}+v_{c 2}}{R_{1}} \\
& R_{1} C_{1} \frac{d\left(v_{c 1}\right)}{d t}=i R_{1}-v_{c 1}+v_{c 2}
\end{aligned}
$$




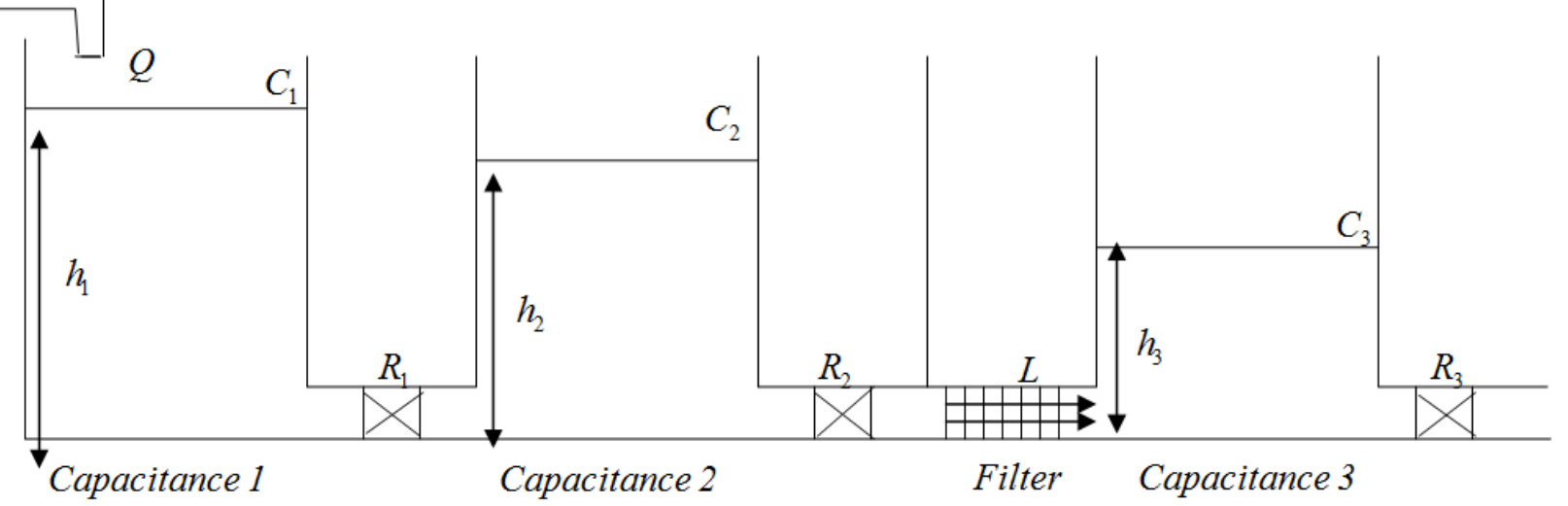

Figure 2. Coupled tank flow system.

L1

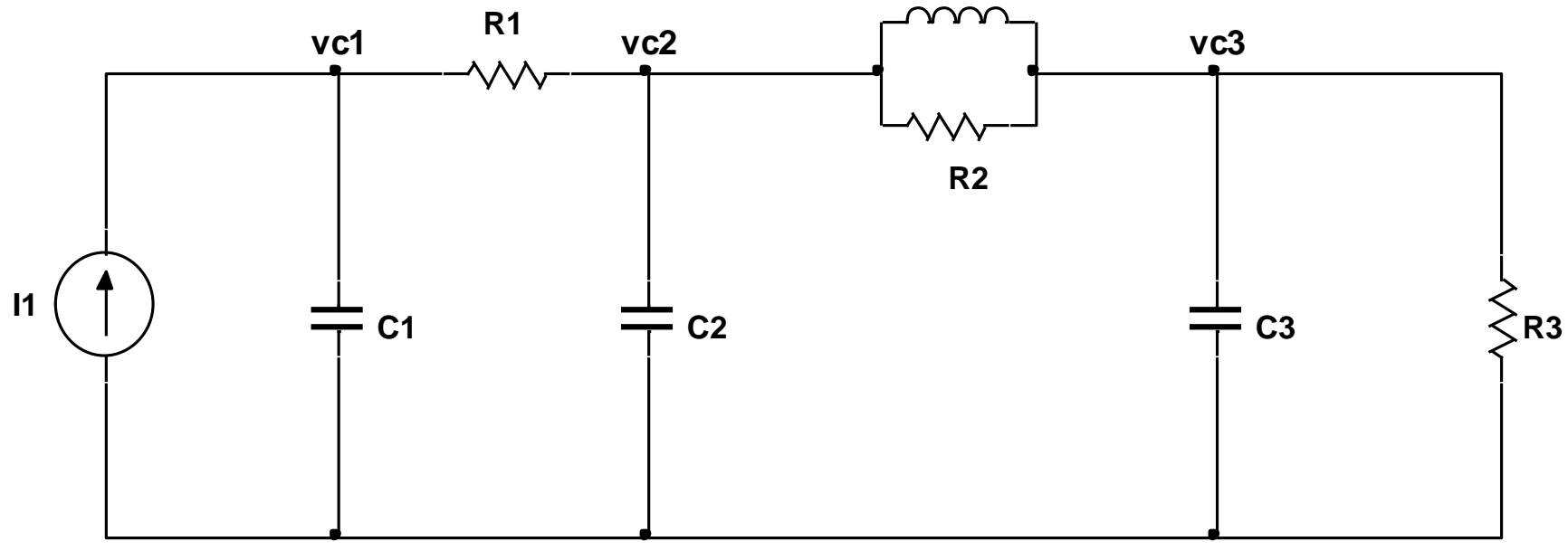

Figure 3. Electrical circuit equivalent.

$\frac{d\left(v_{c 1}\right)}{d t}=\frac{i R_{1}}{R_{1} C_{1}}-\frac{v_{c 1}}{R_{1} C_{1}}+\frac{v_{c 2}}{R_{1} C_{1}}$

$\frac{d\left(v_{c 1}\right)}{d t}=\frac{i}{C_{1}}-\frac{v_{c 1}}{R_{1} C_{1}}+\frac{v_{c 2}}{R_{1} C_{1}}$

$\frac{d\left(v_{c 1}\right)}{d t}=-\frac{v_{c 1}}{R_{1} C_{1}}+\frac{v_{c 2}}{R_{1} C_{1}}+\frac{i}{C_{1}}$

From Equation (9)

$C_{2} \frac{d\left(v_{c 2}\right)}{d t}=\left(\frac{v_{c 1}-v_{c 2}}{R_{1}}\right)-i_{1}$
$C_{2} \frac{d\left(v_{c 2}\right)}{d t}=\frac{\left(v_{c 1}-v_{c 2}\right)}{R_{1}}-i_{1}$

$C_{2} \frac{d\left(v_{c 2}\right)}{d t}=\frac{v_{c 1}-v_{c 2}-R_{1} i_{1}}{R_{1}}$

$R_{1} C_{2} \frac{d\left(v_{c 2}\right)}{d t}=v_{c 1}-v_{c 2}-R_{1} i_{1}$

$\frac{d\left(v_{c 2}\right)}{d t}=\frac{v_{c 1}}{R_{1} C_{2}}-\frac{v_{c 2}}{R_{1} C_{2}}-\frac{R_{1} i_{1}}{R_{1} C_{2}}$

$\frac{d\left(v_{c 2}\right)}{d t}=\frac{v_{c 1}}{R_{1} C_{2}}-\frac{v_{c 2}}{R_{1} C_{2}}-\frac{i_{1}}{C_{2}}$ 
From Equation (10),

$$
L \frac{d\left(i_{1}\right)}{d t}=\frac{L}{R_{2}} \frac{d\left(v_{c 2}\right)}{d t}+v_{c 2}-v_{c 3}
$$

Substituting $\frac{d\left(v_{c 2}\right)}{d t}$ in Equation (13) gives:

$L \frac{d\left(i_{1}\right)}{d t}=\frac{L}{R_{2}}\left(\frac{v_{c 1}}{R_{1} C_{2}}-\frac{v_{c 2}}{R_{1} C_{2}}-\frac{i_{1}}{C_{2}}\right)+v_{c 2}-v_{c 3}$

$L \frac{d\left(i_{1}\right)}{d t}=\frac{L v_{c 1}}{R_{1} R_{2} C_{2}}-\frac{L v_{c 2}}{R_{1} R_{2} C_{2}}-\frac{L i_{1}}{R_{2} C_{2}}+v_{c 2}-v_{c 3}$

$L \frac{d\left(i_{1}\right)}{d t}=\frac{L v_{c 1}-L v_{c 2}-R_{1} L i_{1}+R_{1} R_{2} C_{2} v_{c 2}-R_{1} R_{2} C_{2} v_{c 3}}{R_{1} R_{2} C_{2}}$

$\frac{d\left(i_{1}\right)}{d t}=\frac{L v_{c 1}-L v_{c 2}-R_{1} L i_{1}+R_{1} R_{2} C_{2} v_{c 2}-R_{1} R_{2} C_{2} v_{c 3}}{R_{1} R_{2} C_{2} L}$

$\frac{d\left(i_{1}\right)}{d t}=\frac{L v_{c 1}-L v_{c 2}+R_{1} R_{2} C_{2} v_{c 2}-R_{1} L i_{1}-R_{1} R_{2} C_{2} v_{c 3}}{R_{1} R_{2} C_{2} L}$

$\frac{d\left(i_{1}\right)}{d t}=\frac{L v_{c 1}-\left(L-R_{1} R_{2} C_{2}\right) v_{c 2}-R_{1} L i_{1}-R_{1} R_{2} C_{2} v_{c 3}}{R_{1} R_{2} C_{2} L}$

$R_{1} R_{2} C_{2} L \frac{d\left(i_{1}\right)}{d t}=L v_{c 1}-\left(L-R_{1} R_{2} C_{2}\right) v_{c 2}-R_{1} L i_{1}-R_{1} R_{2} C_{2} v_{c 3}$

$\frac{d\left(i_{1}\right)}{d t}=\frac{L v_{c 1}}{R_{1} R_{2} C_{2} L}-\frac{\left(L-R_{1} R_{2} C_{2}\right) v_{c 2}}{R_{1} R_{2} C_{2} L}-\frac{R_{1} L i_{1}}{R_{1} R_{2} C_{2} L}-\frac{R_{1} R_{2} C_{2} v_{c 3}}{R_{1} R_{2} C_{2} L}$

$\frac{d\left(i_{1}\right)}{d t}=\frac{v_{c 1}}{R_{1} R_{2} C_{2}}-\frac{\left(L-R_{1} R_{2} C_{2}\right) v_{c 2}}{R_{1} R_{2} C_{2} L}-\frac{i_{1}}{R_{2} C_{2}}-\frac{v_{c 3}}{L}$

From Equation (11)

$C_{3} \frac{d\left(v_{c 3}\right)}{d t}=\frac{L}{R_{2}} \frac{d\left(v_{c 2}\right)}{d t}+v_{c 2}-\frac{v_{c 3}}{R_{3}}$

Substituting $\frac{d\left(v_{c 2}\right)}{d t}$ in Equation (13) gives:

$C_{3} \frac{d\left(v_{c 3}\right)}{d t}=\frac{L}{R_{2}}\left(\frac{v_{c 1}}{R_{1} C_{2}}-\frac{v_{c 2}}{R_{1} C_{2}}-\frac{i_{1}}{C_{2}}\right)+v_{c 2}-\frac{v_{c 3}}{R_{3}}$
$C_{3} \frac{d\left(v_{c 3}\right)}{d t}=\frac{L v_{c 1}}{R_{1} R_{2} C_{2}}-\frac{L v_{c 2}}{R_{1} R_{2} C_{2}}-\frac{L i_{1}}{R_{2} C_{2}}+v_{c 2}-\frac{v_{c 3}}{R_{3}}$

$C_{3} \frac{d\left(v_{c 3}\right)}{d t}=\frac{R_{3} L v_{c 1}-R_{3} L v_{c 2}-R_{1} R_{3} L i_{1}+R_{1} R_{2} R_{3} C_{2} v_{c 2}-R_{1} R_{2} C_{2} v_{c 3}}{R_{1} R_{2} R_{3} C_{2}}$

$\frac{d\left(v_{c 3}\right)}{d t}=\frac{R_{3} L v_{c 1}-R_{3} L v_{c 2}-R_{1} R_{3} L i_{1}+R_{1} R_{2} R_{3} C_{2} v_{c 2}-R_{1} R_{2} C_{2} v_{c 3}}{R_{1} R_{2} R_{3} C_{2} C_{3}}$

$\frac{d\left(v_{c 3}\right)}{d t}=\frac{R_{3} L v_{c 1}-R_{3} L v_{c 2}+R_{1} R_{2} R_{3} C_{2} v_{c 2}-R_{1} R_{3} L i_{1}-R_{1} R_{2} C_{2} v_{c 3}}{R_{1} R_{2} R_{3} C_{2} C_{3}}$

$\frac{d\left(v_{c 3}\right)}{d t}=\frac{R_{3} L v_{c 1}-R_{3} L v_{c 2}+R_{1} R_{2} R_{3} C_{2} v_{c 2}-R_{1} R_{3} L i_{1}-R_{1} R_{2} C_{2} v_{c 3}}{R_{1} R_{2} R_{3} C_{2} C_{3}}$

$\frac{d\left(v_{c 3}\right)}{d t}=\frac{R_{3} L v_{c 1}-R_{3}\left(L-R_{1} R_{2} C_{2}\right) v_{c 2}-R_{1} R_{3} L i_{1}-R_{1} R_{2} C_{2} v_{c 3}}{R_{1} R_{2} R_{3} C_{2} C_{3}}$

$\frac{d\left(v_{c 3}\right)}{d t}=\frac{R_{3} L v_{c 1}}{R_{1} R_{2} R_{3} C_{2} C_{3}}-\frac{R_{3}\left(L-R_{1} R_{2} C_{2}\right) v_{c 2}}{R_{1} R_{2} R_{3} C_{2} C_{3}}-\frac{R_{1} R_{3} L i_{1}}{R_{1} R_{2} R_{3} C_{2} C_{3}}-\frac{R_{1} R_{2} C_{2} v_{c 3}}{R_{1} R_{2} R_{3} C_{2} C_{3}}$

$\frac{d\left(v_{c 3}\right)}{d t}=\frac{L v_{c 1}}{R_{1} R_{2} C_{2} C_{3}}-\frac{\left(L-R_{1} R_{2} C_{2}\right) v_{c 2}}{R_{1} R_{2} C_{2} C_{3}}-\frac{L i_{1}}{R_{2} C_{2} C_{3}}-\frac{v_{c 3}}{R_{3} C_{3}}$

The resulting state equations are given by:

$$
\left\{\begin{array}{l}
\frac{d\left(v_{c 1}\right)}{d t}=-\frac{v_{c 1}}{R_{1} C_{1}}+\frac{v_{c 2}}{R_{1} C_{1}}+\frac{i}{C_{1}} \\
\frac{d\left(v_{c 2}\right)}{d t}=\frac{v_{c 1}}{R_{1} C_{2}}-\frac{v_{c 2}}{R_{1} C_{2}}-\frac{i_{1}}{C_{2}} \\
\frac{d\left(i_{1}\right)}{d t}=\frac{v_{c 1}}{R_{1} R_{2} C_{2}}-\frac{\left(L-R_{1} R_{2} C_{2}\right) v_{c 2}}{R_{1} R_{2} C_{2} L}-\frac{i_{1}}{R_{2} C_{2}}-\frac{v_{c 3}}{L} \\
\frac{d\left(v_{c 3}\right)}{d t}=\frac{L v_{c 1}}{R_{1} R_{2} C_{2} C_{3}}-\frac{\left(L-R_{1} R_{2} C_{2}\right) v_{c 2}}{R_{1} R_{2} C_{2} C_{3}}-\frac{L i_{1}}{R_{2} C_{2} C_{3}}-\frac{v_{c 3}}{R_{3} C_{3}}
\end{array}\right\}
$$

The state equation's equivalent in $x$ form is thus:

$$
\left\{\begin{array}{l}
\dot{x}_{1}=-\frac{x_{1}}{R_{1} C_{1}}+\frac{x_{2}}{R_{1} C_{1}}+\frac{u}{C_{1}} \\
\dot{x}_{2}=\frac{x_{1}}{R_{1} C_{2}}-\frac{x_{2}}{R_{1} C_{2}}-\frac{x_{3}}{C_{2}} \\
\dot{x}_{3}=\frac{x_{1}}{R_{1} R_{2} C_{2}}-\frac{\left(L-R_{1} R_{2} C_{2}\right) x_{2}}{R_{1} R_{2} C_{2} L}-\frac{x_{3}}{R_{2} C_{2}}-\frac{x_{4}}{L} \\
\dot{x}_{4}=\frac{L x_{1}}{R_{1} R_{2} C_{2} C_{3}}-\frac{\left(L-R_{1} R_{2} C_{2}\right) x_{2}}{R_{1} R_{2} C_{2} C_{3}}-\frac{L x_{3}}{R_{2} C_{2} C_{3}}-\frac{x_{4}}{R_{3} C_{3}}
\end{array}\right\}
$$

In vector-matrix form, the process control equation is given as: 


$$
\left[\begin{array}{l}
\dot{x}_{1} \\
\dot{x}_{2} \\
\dot{x}_{3} \\
\dot{x}_{4}
\end{array}\right]=\left[\begin{array}{cccc}
-\frac{1}{\mathrm{R}_{1} \mathrm{C}_{1}} & \frac{1}{\mathrm{R}_{1} \mathrm{C}_{1}} & 0 & 0 \\
\frac{1}{\mathrm{R}_{1} \mathrm{C}_{2}} & -\frac{1}{\mathrm{R}_{1} \mathrm{C}_{2}} & -\frac{1}{\mathrm{C}_{2}} & 0 \\
\frac{1}{\mathrm{R}_{1} R_{2} C_{2}} & -\frac{\left(L-R_{1} R_{2} C_{2}\right)}{R_{1} R_{2} C_{2} \mathrm{~L}} & -\frac{1}{R_{2} C_{2}} & -\frac{1}{\mathrm{~L}} \\
\frac{\mathrm{L}}{\mathrm{R}_{1} R_{2} C_{2} C_{3}} & -\frac{\left(\mathrm{L}-\mathrm{R}_{1} R_{2} C_{2}\right)}{\mathrm{R}_{1} R_{2} \mathrm{C}_{2} \mathrm{C}_{3}} & -\frac{L}{R_{2} C_{2} \mathrm{C}_{3}} & -\frac{1}{\mathrm{R}_{3} \mathrm{C}_{3}}
\end{array}\right]\left[\begin{array}{c}
x_{1} \\
x_{2} \\
x_{3} \\
x_{4}
\end{array}\right]+\left[\begin{array}{c}
\frac{1}{\mathrm{C}_{1}} \\
0 \\
0 \\
0
\end{array}\right][u]
$$

The output equation is thus:

$$
y=\left[\begin{array}{llll}
0 & 0 & 0 & 1
\end{array}\right]\left[\begin{array}{l}
x_{1} \\
x_{2} \\
x_{3} \\
x_{4}
\end{array}\right]
$$

$x$ is the state vector while $y$ is the response or output vector.

\section{STATE VARIABLES REPRESENTATION}

The merit of the state-variable method is that it results easily to the form amendable to digital and/or analog computer methods of solution (Perdikaris, 1996). Sachet water processing plant can be represented in state variable form as:

$$
\begin{aligned}
& \dot{x}=A^{*} x+B^{*} u \\
& y=C x
\end{aligned}
$$

\section{Where}

$$
\dot{x}=\left[\begin{array}{l}
\dot{x}_{1} \\
\dot{x}_{2} \\
\dot{x}_{3} \\
\dot{x}_{4}
\end{array}\right] A=\left[\begin{array}{ccccc}
-\frac{1}{\mathrm{R}_{1} \mathrm{C}_{1}} & \frac{1}{\mathrm{R}_{1} \mathrm{C}_{1}} & 0 & 0 \\
\frac{1}{\mathrm{R}_{1} \mathrm{C}_{2}} & -\frac{1}{\mathrm{R}_{1} \mathrm{C}_{2}} & -\frac{1}{\mathrm{C}_{2}} & 0 \\
\frac{1}{\mathrm{R}_{1} R_{2} C_{2}} & -\frac{\left(L-R_{1} R_{2} C_{2}\right)}{R_{1} R_{2} C_{2} \mathrm{~L}} & -\frac{1}{R_{2} C_{2}} & -\frac{1}{\mathrm{~L}} \\
\frac{\mathrm{L}}{\mathrm{R}_{1} R_{2} C_{2} C_{3}} & -\frac{\left(\mathrm{L}-\mathrm{R}_{1} R_{2} C_{2}\right)}{\mathrm{R}_{1} R_{2} C_{2} C_{3}} & -\frac{L}{R_{2} C_{2} \mathrm{C}_{3}} & -\frac{1}{\mathrm{R}_{3} \mathrm{C}_{3}}
\end{array}\right] ; x=\left[\begin{array}{l}
x_{1} \\
x_{2} \\
x_{3} \\
x_{4}
\end{array}\right]
$$$$
B=\left[\begin{array}{l}
\frac{1}{C_{1}} \\
0 \\
0 \\
0
\end{array}\right] ; \quad y=x ; C=\left[\begin{array}{llll}
0 & 0 & 0 & 1
\end{array}\right]
$$

Table 3. Sachet water processing plant parameters.

\begin{tabular}{rcccccc}
\hline$R_{1}$ & $R_{2}$ & $R_{3}$ & $L$ & $C_{1}$ & $C_{2}$ & $C_{3}$ \\
\hline 0.1 & 0.1 & 1.0 & 1.0 & $1 \mathrm{e}-03$ & $1 \mathrm{e}-03$ & $1000 \mathrm{e}-03$ \\
$(18) .3$ & 0.3 & 3.0 & 3.0 & $3 \mathrm{e}-03$ & $3 \mathrm{e}-03$ & $1300 \mathrm{e}-03$ \\
0.5 & 0.5 & 5.0 & 5.0 & $5 \mathrm{e}-03$ & $5 \mathrm{e}-03$ & $1500 \mathrm{e}-03$ \\
0.7 & 0.7 & 7.0 & 7.0 & $7 \mathrm{e}-03$ & $7 \mathrm{e}-03$ & $1700 \mathrm{e}-03$ \\
0.9 & 0.9 & 9.0 & 9.0 & $9 \mathrm{e}-03$ & $9 \mathrm{e}-03$ & $1900 \mathrm{e}-03$ \\
\hline
\end{tabular}

$x$ is the state vector while $y$ is the response or output vector. $A$ is the coefficient matrix of the process and is of order $(m \times m) . B$ is the driving matrix of $\operatorname{order}(n \times p)$, and $C$ is the output matrix of order $(q \times n)$, which satisfied the rules of matrix multiplication. The above defined matrix operations are carried out on a digital computer using MATLAB software (Mathworks, 2002).

\section{METHODOLOGY}

Solution of resulting state equation is achieved numerically thus, the computer study of a modified mathematical model description involving the problem variables are instrumented on the computer and the parameter values are adjusted, thereby varying the matrices $A, B, C$ so as to obtain/predict the behaviour of the actual system. From the model equation above, output $y$ depends on the state equation $x$ which is $x_{4}$, that is $y=x_{4}$.

Therefore, $x$ and $y$ are dependent variables to be simulated.

The above equations contain all that we need to know about the theory of process control (flow) in a sachet water plant being studied. Solving the time domain $\dot{X}(t)=A x(t)+B u(t)$ and $Y(t)=C x(t)+D u(t)$ where $\mathrm{D}=0$. Using Ordinary Differential Equation (ODE 45) of MATLAB Software, the results will be obtained graphically.

\section{SIMULATION AND RESULTS}

Table 3 shows the sachet water processing plant parameters used for the simulation.

In order to study the dynamic behaviour of the process, the state-variable form of Equation (18), were solved numerically using the differential method. By incorporating the developed algorithm into the MATLAB m-file (MATLAB, 1997), the system time response curves for the voltage across capacitor, and flow of current through the inductor at various coordinate systems are developed.

Response of voltages across the capacitors graphs are shown in Figures 4 to 18 and 24 to 38, while Figures 19 to 23 show the Response of current through the inductor graph for the system.

The following is applicable to Figures 4 to 38 . 


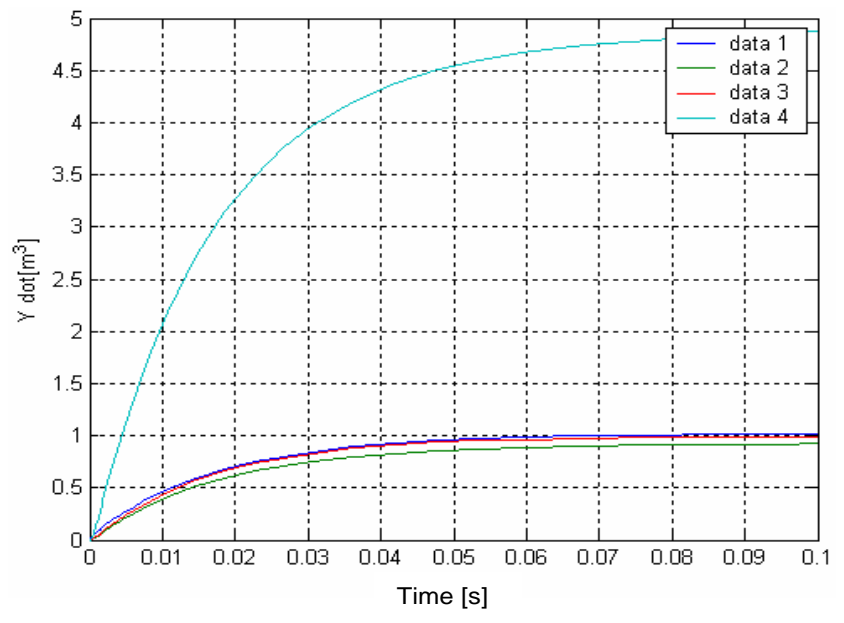

Figure 4. Effect of Restriction to flow on the Process, with $R_{1}$ $=0.1$.

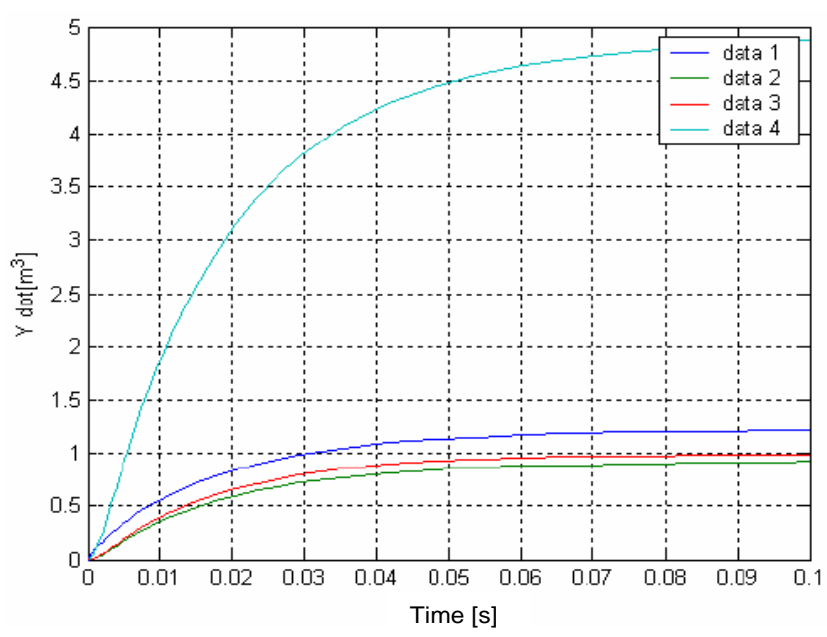

Figure 5. Effect of Restriction to flow on the Process, with $R_{1}$ $=0.3$.

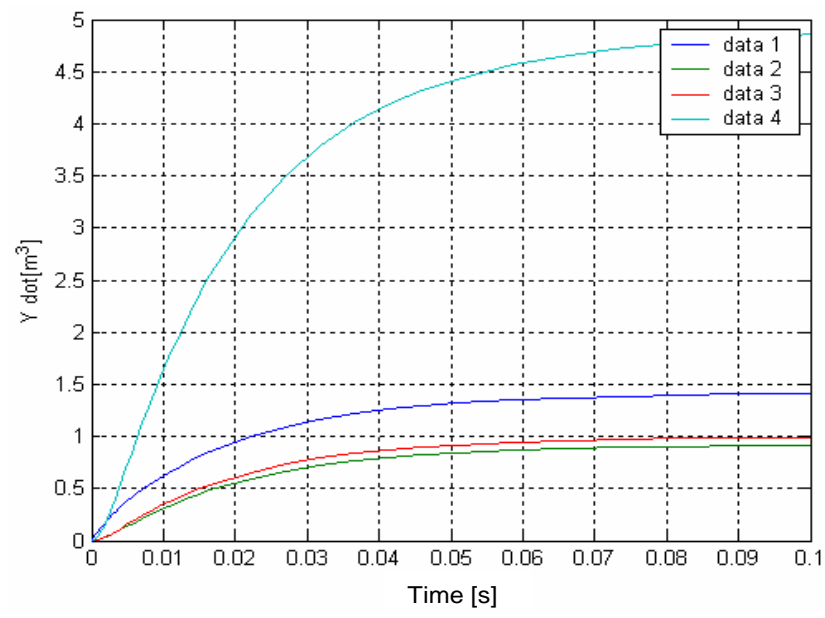

Figure 6. Effect of Restriction to flow on the Process, with $R_{1}$ $=0.5$.

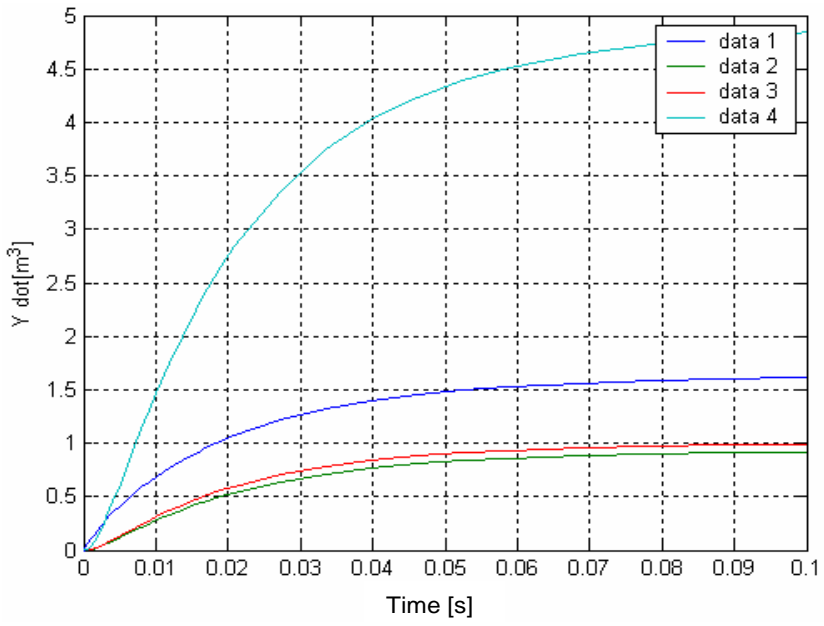

Figure 7. Effect of Restriction to flow on the Process, with $R_{1}$ $=0.7$.

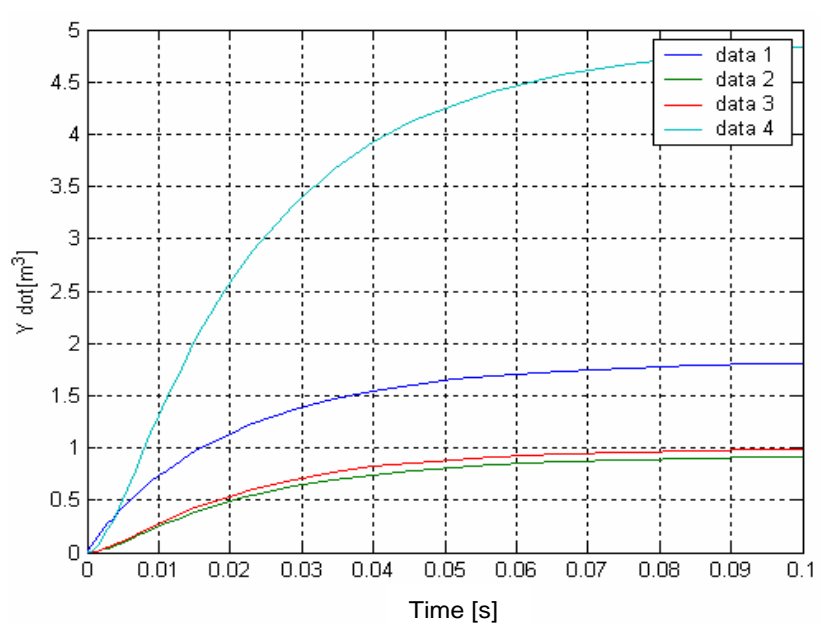

Figure 8. Effect of Restriction to flow on the Process, with $R_{1}$ $=0.9$.

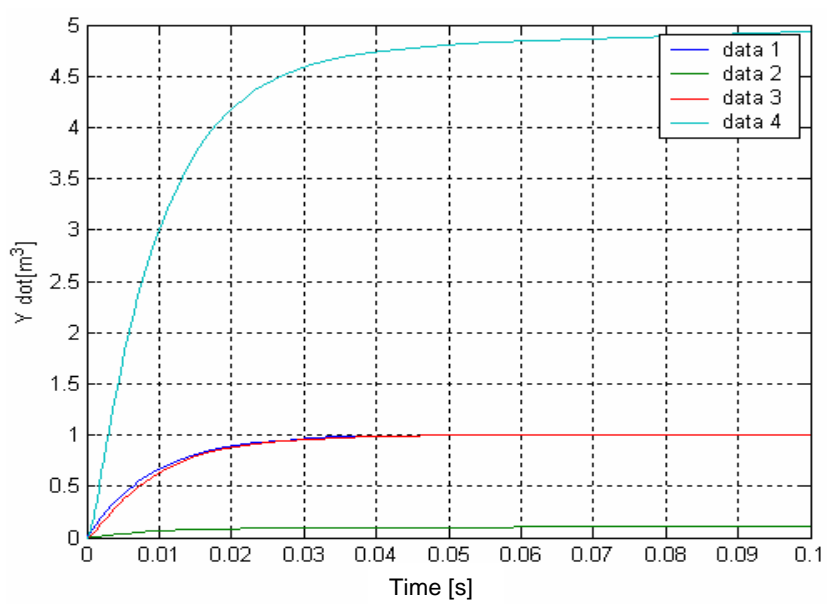

Figure 9. Effect of Restriction to flow on the Process, with $R_{2}$ $=0.1$. 


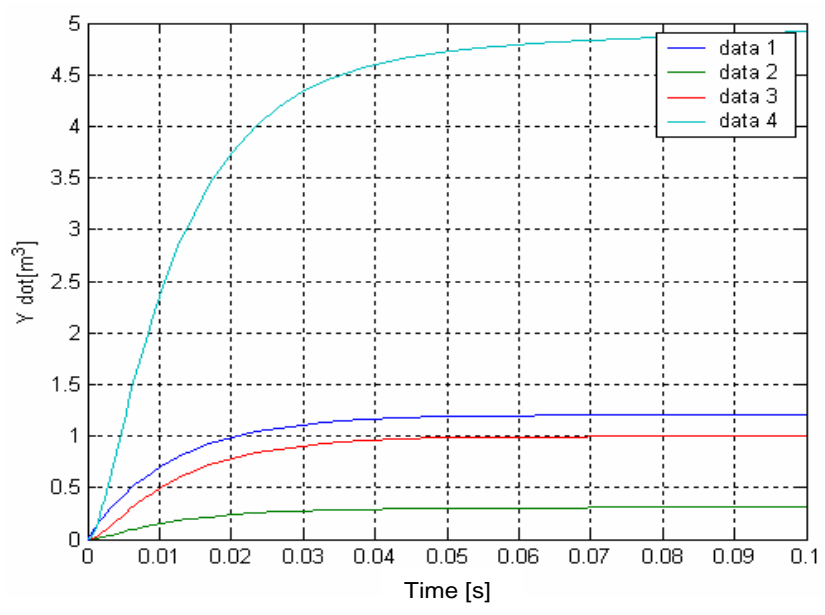

Figure 10. Effect of restriction to flow on the process, with $R_{2}$ $=0.3$.

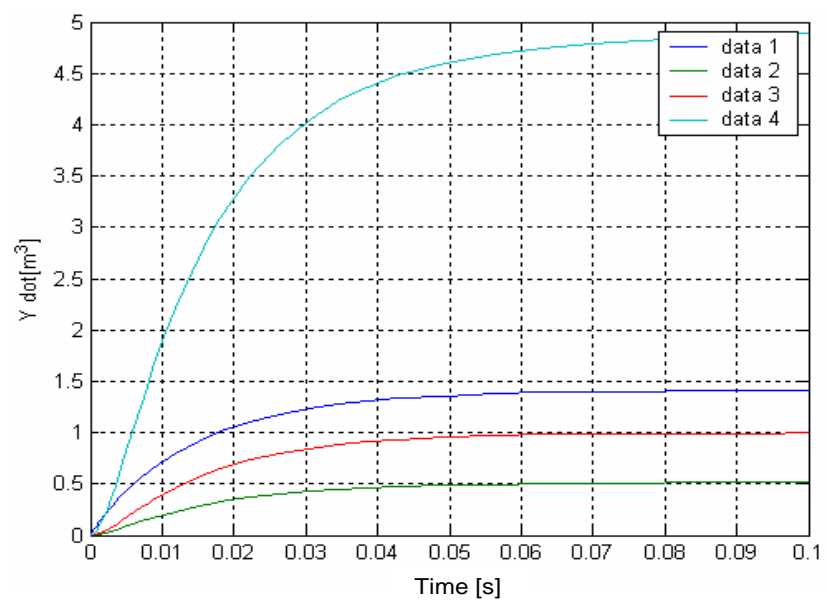

Figure 11. Effect of restriction to flow on the process, with $R_{2}$ $=0.5$.

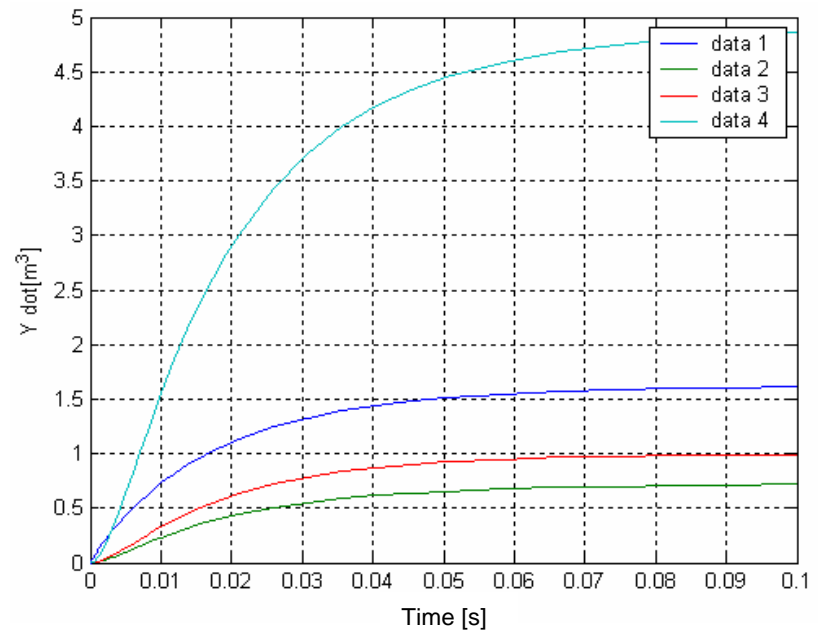

Figure 12. Effect of restriction to flow on the process, with $R_{2}$ $=0.7$.

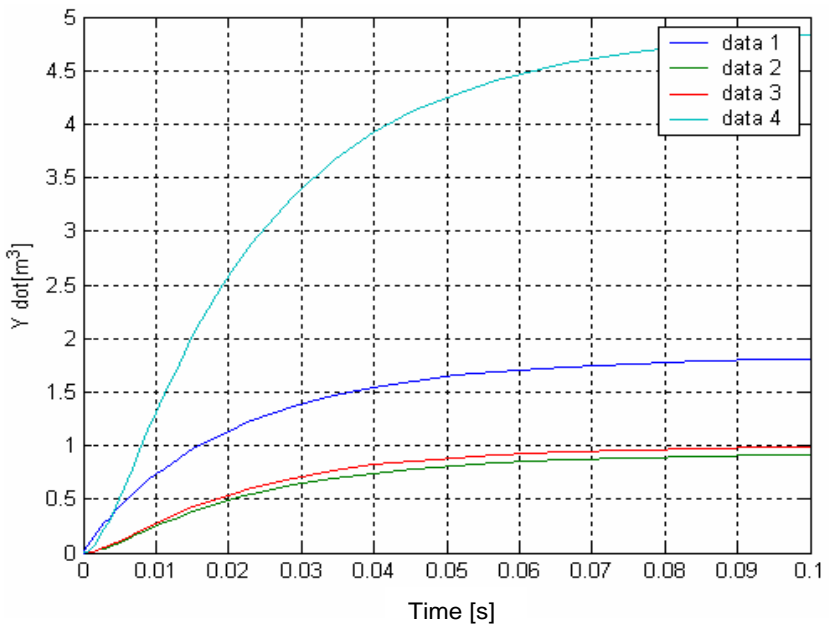

Figure 13. Effect of restriction to flow on the Process, with $R_{2}=$ 0.9 .

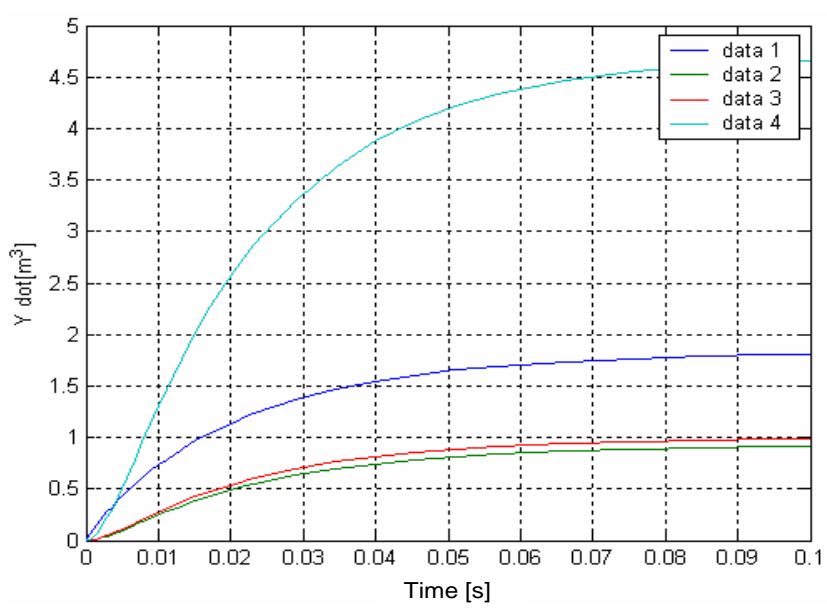

Figure 14. Effect of restriction to flow on the process, with $R_{3}$ $=1.0$.

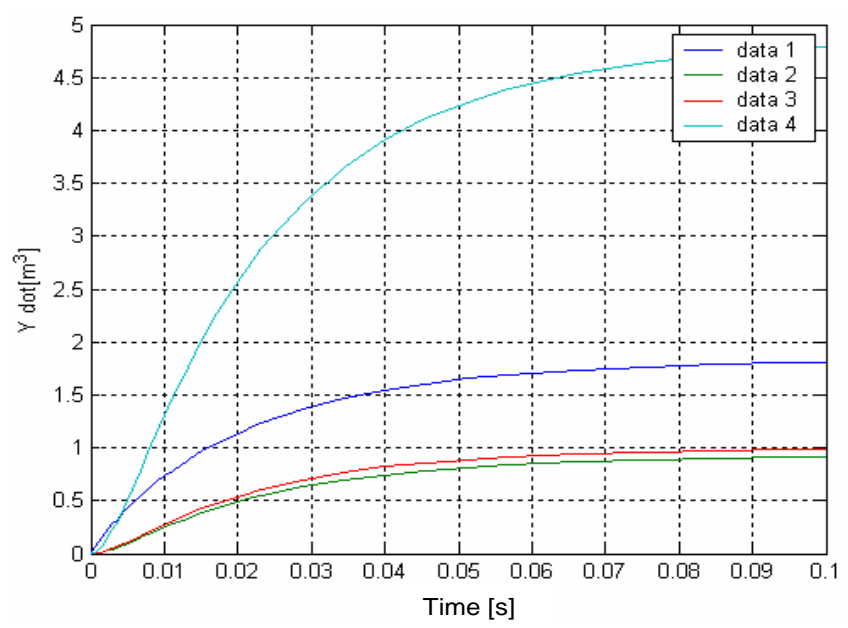

Figure 15. Effect of restriction to flow on the process, with $R_{3}$ $=3.0$. 


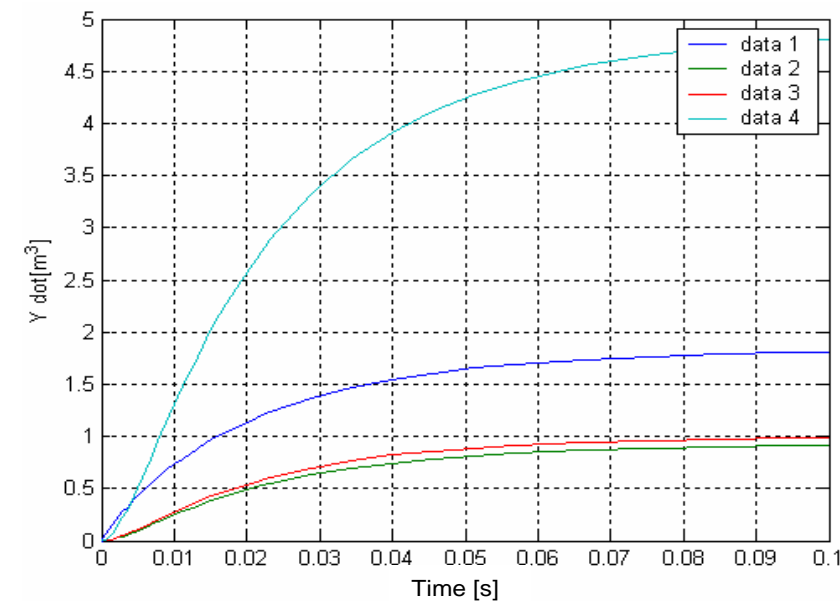

Figure 16. Effect of restriction to flow on the process, with $R_{3}$ $=5.0$.

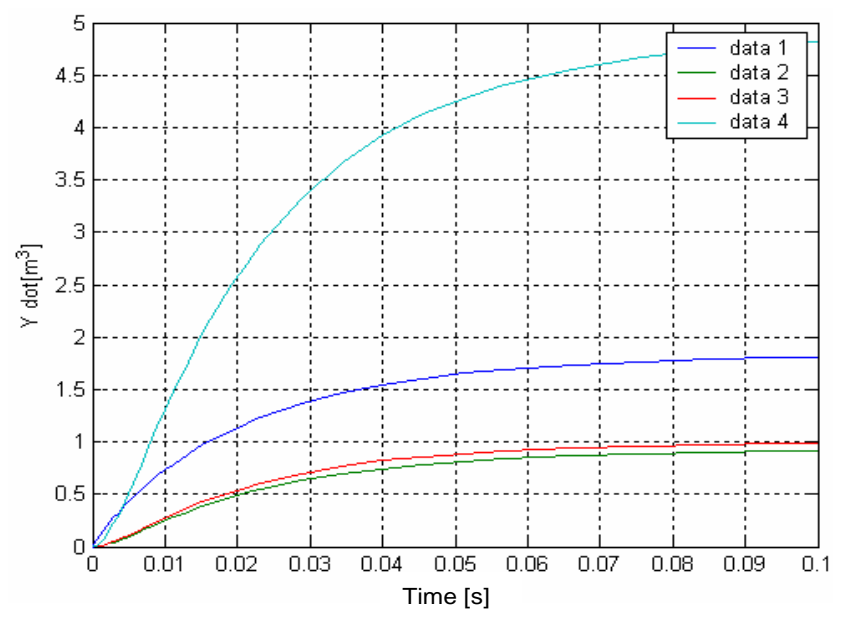

Figure 17. Effect of restriction to flow on the process, with $R_{3}$ $=7.0$.

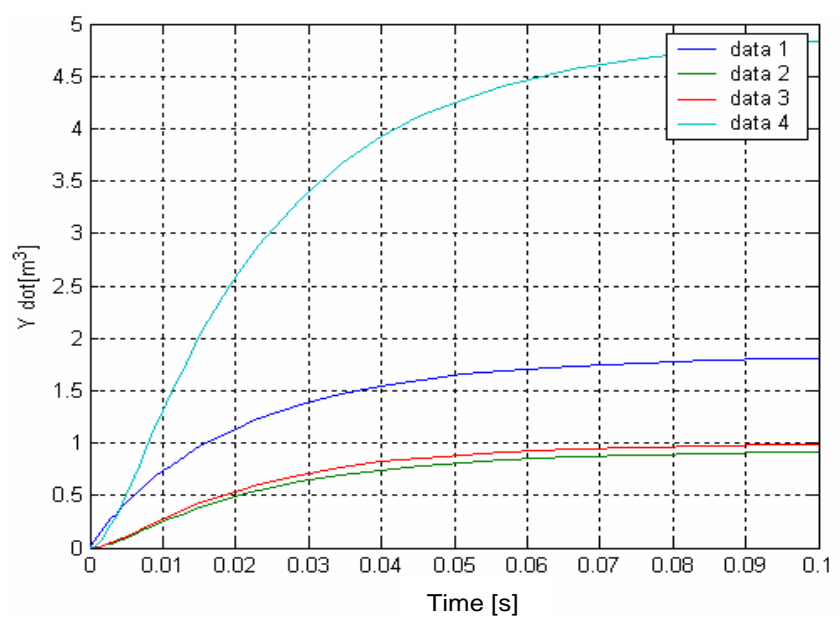

Figure 18. Effect of restriction to flow on the process, with $R_{3}$ $=9.0$.

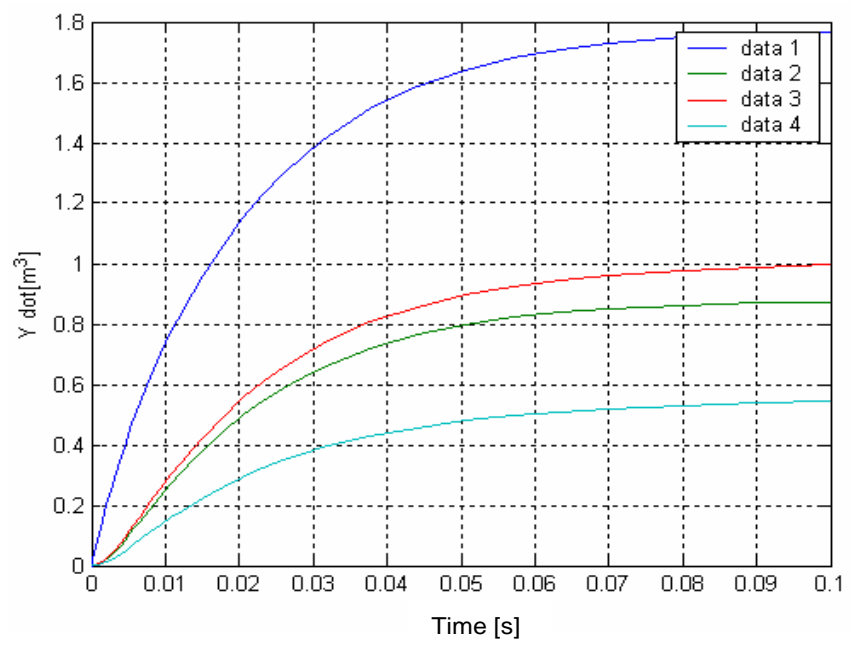

Figure 19. Effect of wound string on the process, with $L=1.0$.

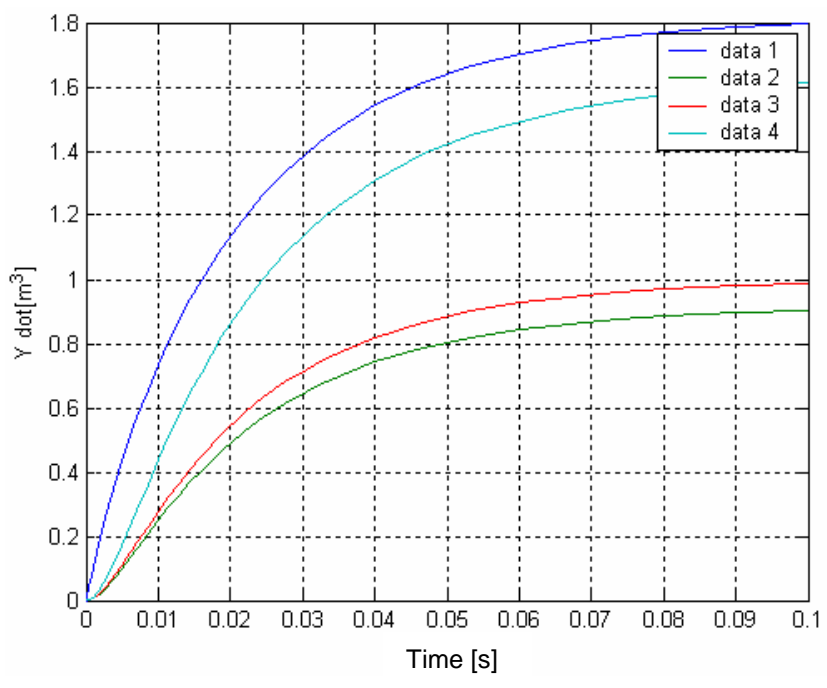

Figure 20. Effect of wound string on the process, with $L=3.0$.

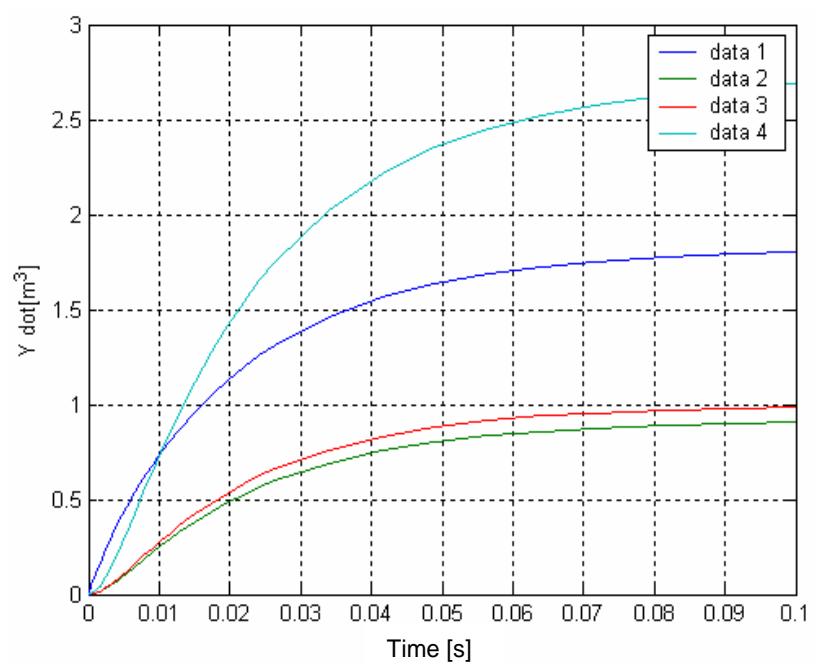

Figure 21. Effect of wound string on the process, with $L=5.0$. 


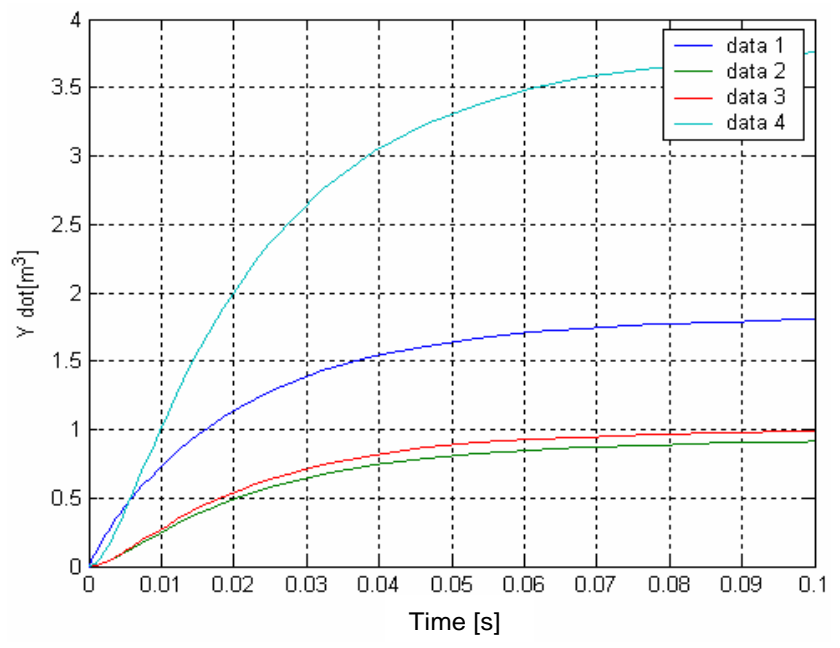

Figure 22. Effect of wound string on the process, with $L=7.0$.

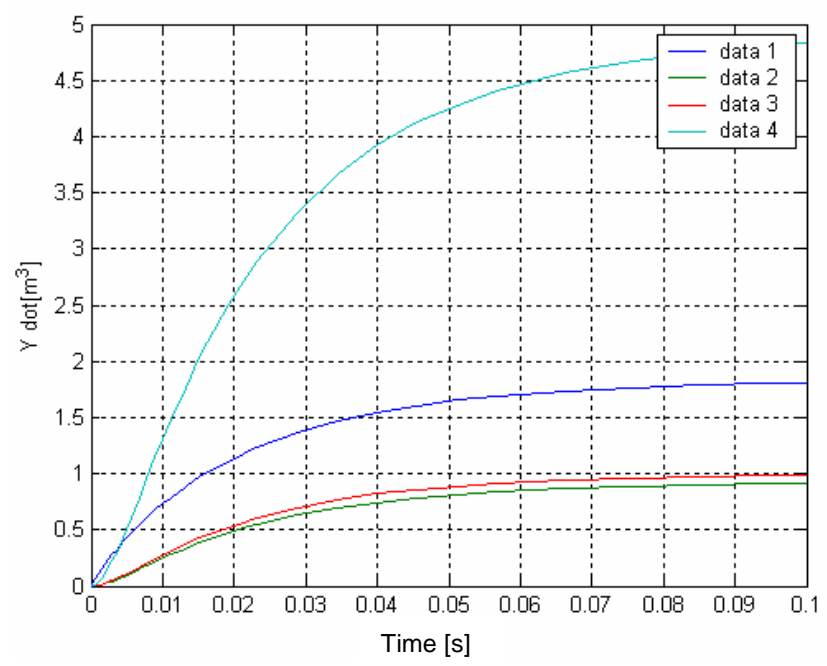

Figure 23. Effect of wound string on the process, with $L=9.0$.

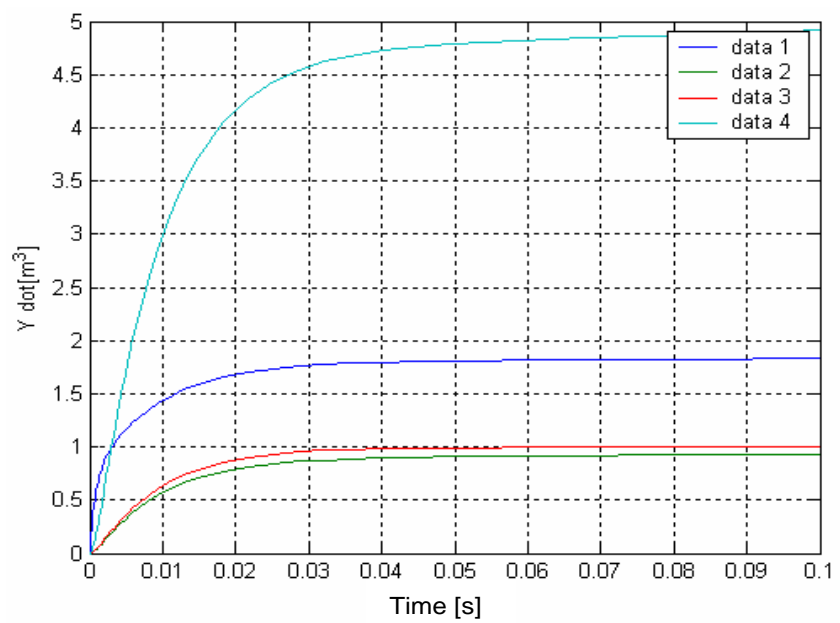

Figure 24. Effect of the capacity of tank on the process, with $C_{1}=1 \mathrm{e}-03$.

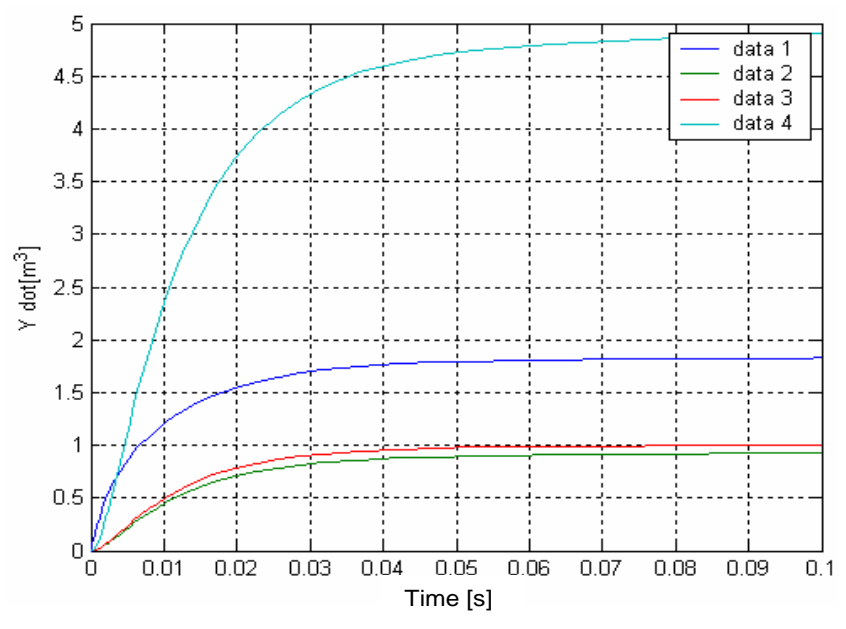

Figure 25. Effect of the capacity of tank on the process, with $C_{1}=3 e-03$.

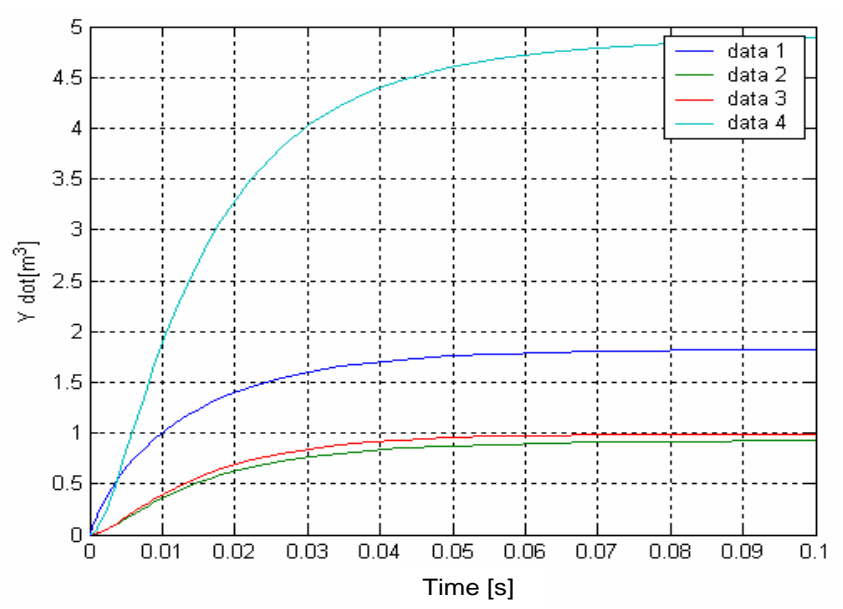

Figure 26. Effect of the capacity of tank on the process, with $C_{1}=5 \mathrm{e}-03$.

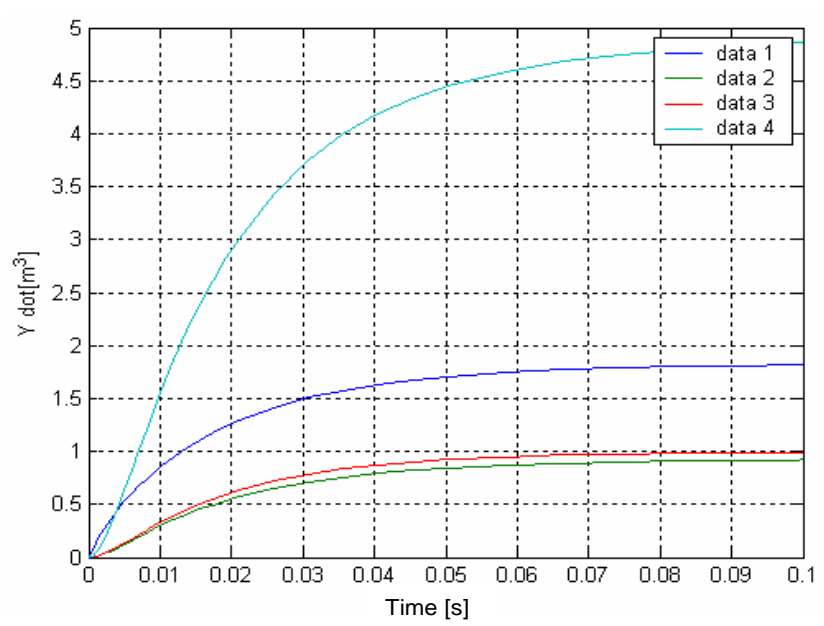

Figure 27. Effect of the capacity of tank on the process, with $C_{1}=7 e-03$. 


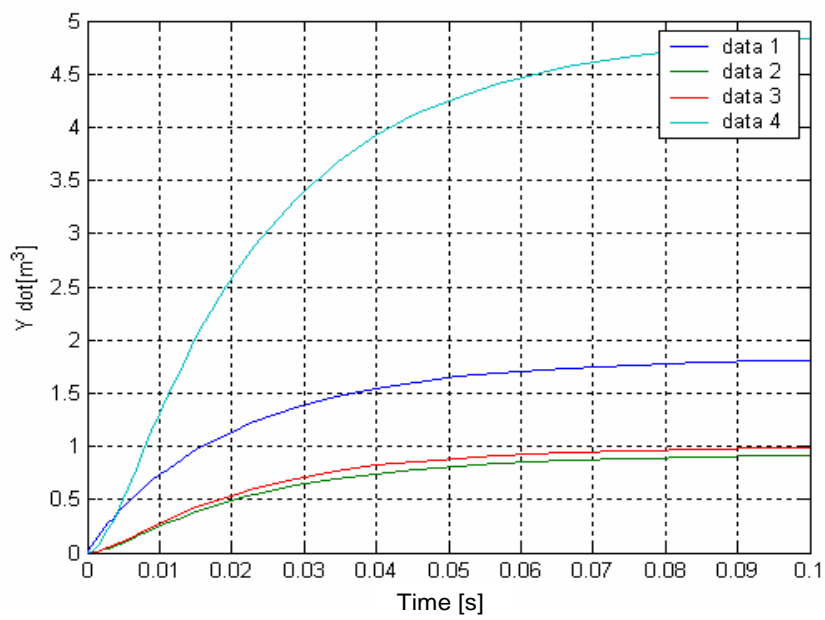

Figure 28. Effect of the capacity of tank on the process, with $C_{1}=9 \mathrm{e}-03$.

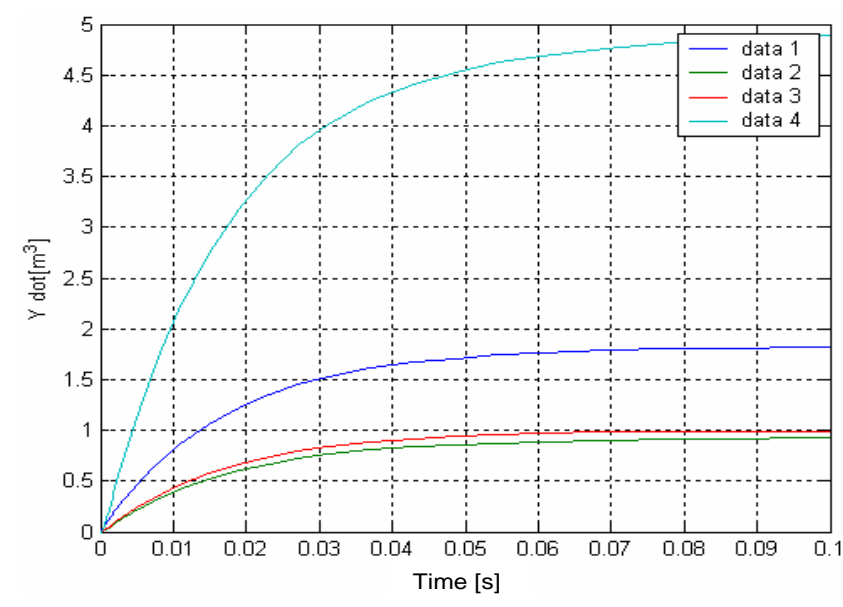

Figure 29. Effect of the capacity of tank on the process, with $C_{2}=1 \mathrm{e}-03$.

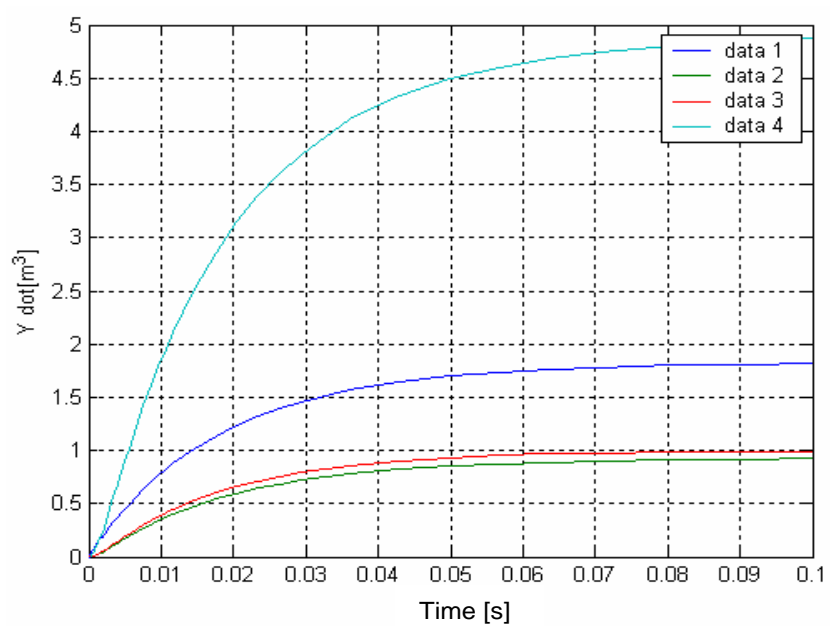

Figure 30. Effect of the capacity of tank on the process, with $C_{2}=3 e-03$.

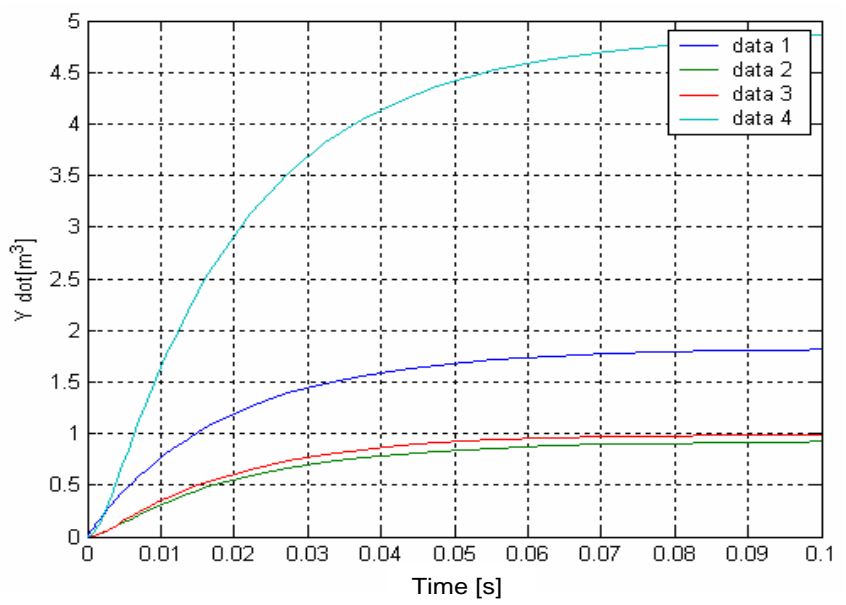

Figure 31. Effect of the capacity of tank on the process, with $C_{2}=5 \mathrm{e}-03$.

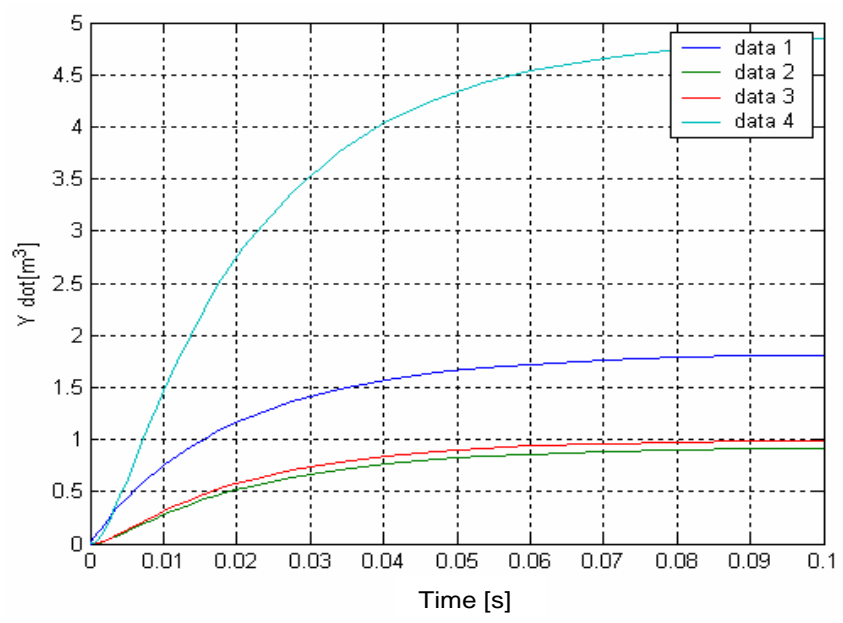

Figure 32. Effect of the capacity of tank on the process, with $C_{2}=7$ e-03.

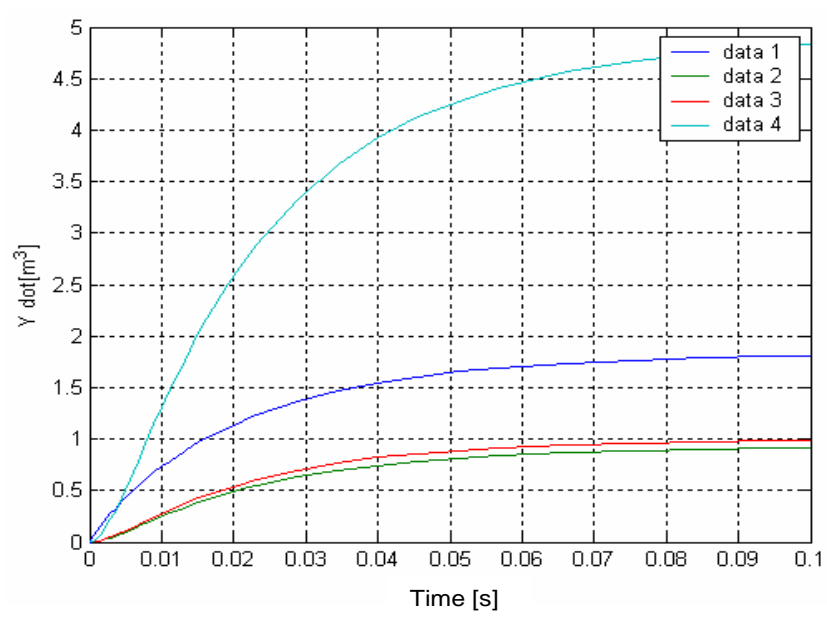

Figure 33. Effect of the capacity of tank on the process, with $C_{2}=9 \mathrm{e}-03$. 


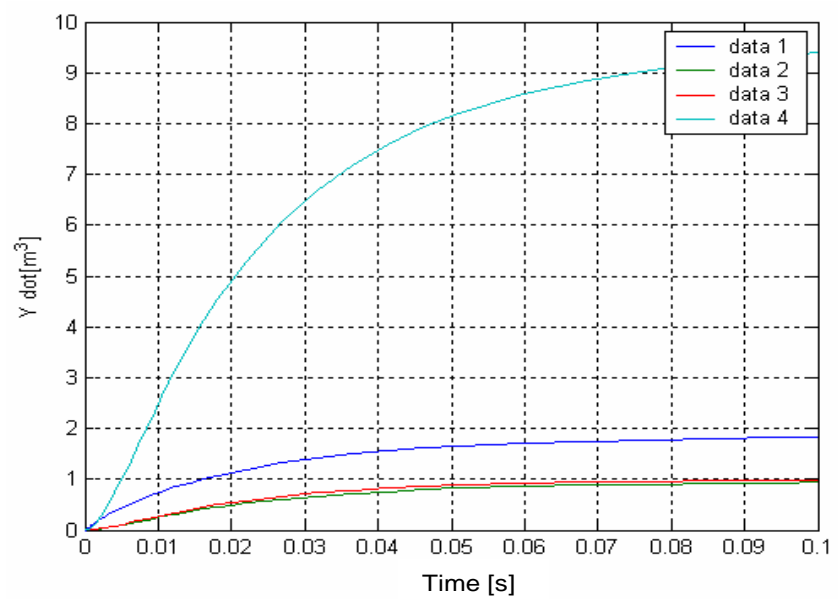

Figure 34. Effect of the capacity of tank on the process, with $C_{3}=1000 \mathrm{e}-03$.

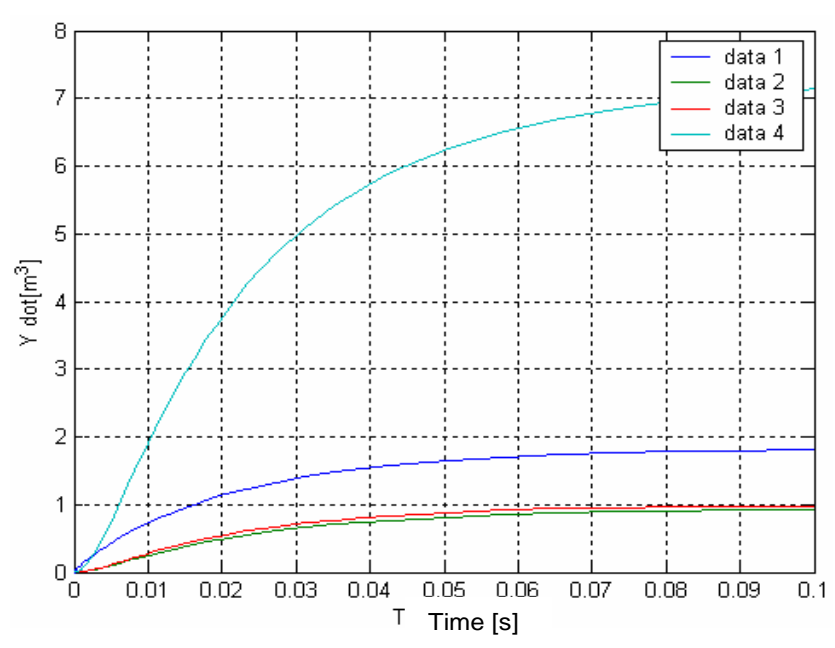

Figure 35. Effect of the capacity of tank on the PROCESS, with $C_{3}=1300 \mathrm{e}-03$.

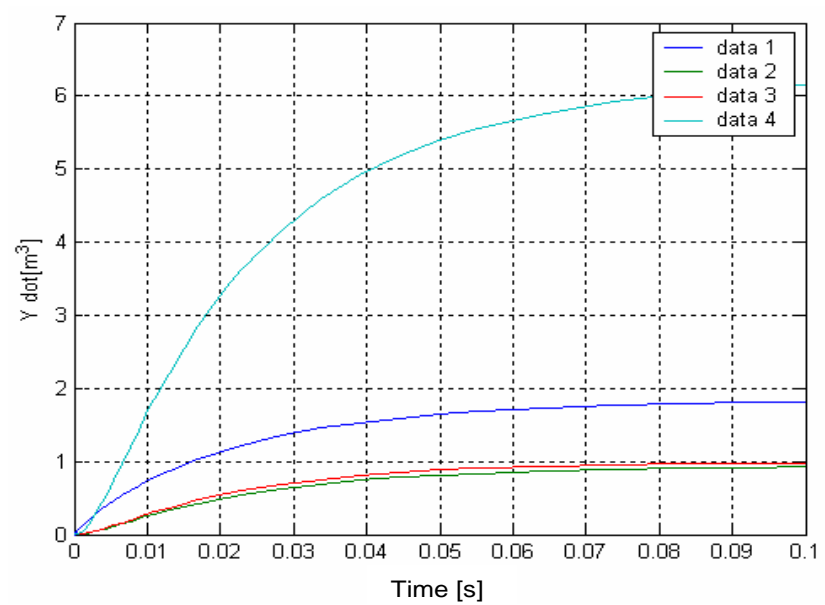

Figure 36. Effect of the capacity of tank on the process, with $C_{3}=1500 \mathrm{e}-03$.

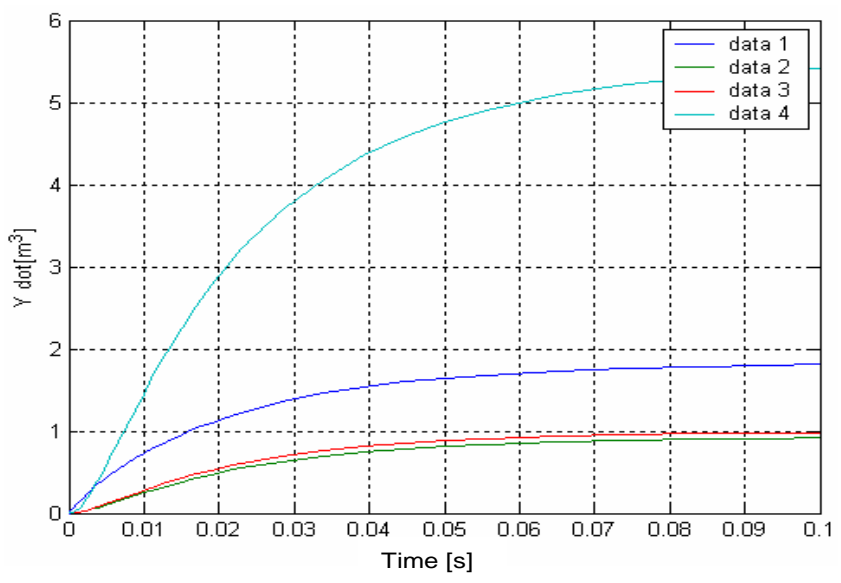

Figure 37. Effect of the capacity of tank on the process, with $C_{3}=1700 \mathrm{e}-03$.

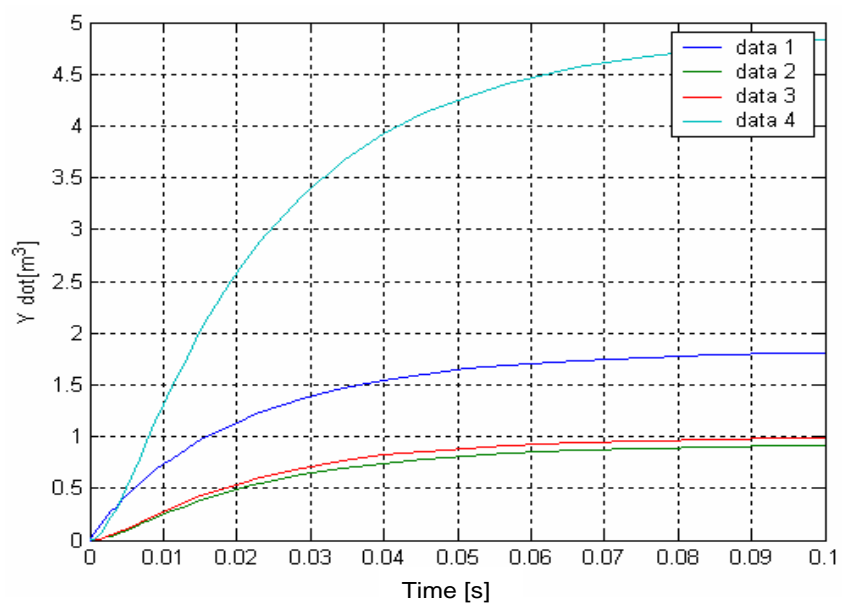

Figure 38. Effect of the capacity of tank on the process, with $C_{3}=1900 \mathrm{e}-03$.

\section{Data 1}

$v_{c 1}=h_{1}$ (voltage across capacitor 1 , as water level of tank 1$)$.

Data 2

$v_{c 2}=h_{2}$ (voltage across capacitor 2, as water level of tank 2). Data 3

$i_{1}=Q_{1}$ (flow of current through the inductor, as rate of water flow through the filter).

Data 4

$v_{c 3}=h_{3}$ (voltage across capacitor 3, as water level of tank 3).

\section{Vertical Line}

$Y \operatorname{dot}\left[\mathrm{m}^{3}\right]=($ Response of voltages $[\mathrm{v}]$ and current $[\mathrm{A}]$ to change(s) in the RLC circuit;

as Response of water levels[m] and rate of water flow[cub$\mathrm{m} / \mathrm{min}$ ] to

change(s) in system parameters).

Horizontal Line

Time $[\mathrm{s}]=$ (model time; real time). 
Table 4. Table of values with $R_{1}$ varied while other parameters were kept constant.

\begin{tabular}{ccccccccccc}
\hline$R_{1}$ & $R_{2}$ & $R_{3}$ & $L$ & $C_{1}$ & $C_{2}$ & $C_{3}$ & $v_{c 1}$ & $v_{c 2}$ & $i$ & $v_{c 3}$ \\
\hline 0.1 & 0.9 & 9.0 & 9.0 & $9 \mathrm{e}-03$ & $9 \mathrm{e}-03$ & $1900 \mathrm{e}-03$ & 1.0232 & 0.9237 & 0.9904 & 4.8779 \\
0.3 & 0.9 & 9.0 & 9.0 & $9 \mathrm{e}-03$ & $9 \mathrm{e}-03$ & $1900 \mathrm{e}-03$ & 1.2206 & 0.9222 & 0.9895 & 4.8698 \\
0.5 & 0.9 & 9.0 & 9.0 & $9 \mathrm{e}-03$ & $9 \mathrm{e}-03$ & $1900 \mathrm{e}-03$ & 1.4168 & 0.9200 & 0.9878 & 4.8577 \\
0.7 & 0.9 & 9.0 & 9.0 & $9 \mathrm{e}-03$ & $9 \mathrm{e}-03$ & $1900 \mathrm{e}-03$ & 1.6121 & 0.9175 & 0.9858 & 4.8442 \\
0.9 & 0.9 & 9.0 & 9.0 & $9 \mathrm{e}-03$ & $9 \mathrm{e}-03$ & $1900 \mathrm{e}-03$ & 1.8055 & 0.9142 & 0.9830 & 4.8269 \\
\hline
\end{tabular}

Table 5. Table of values with $R_{2}$ varied while other parameters were kept constant.

\begin{tabular}{ccccccccccc}
\hline$R_{2}$ & $R_{1}$ & $R_{3}$ & $L$ & $C_{1}$ & $C_{2}$ & $C_{3}$ & $v_{c 1}$ & $v_{c 2}$ & $i$ & $v_{c 3}$ \\
\hline 0.1 & 0.9 & 9.0 & 9.0 & $9 \mathrm{e}-03$ & $9 \mathrm{e}-03$ & $1900 \mathrm{e}-03$ & 1.0042 & 0.1046 & 0.9991 & 4.9362 \\
0.3 & 0.9 & 9.0 & 9.0 & $9 \mathrm{e}-03$ & $9 \mathrm{e}-03$ & $1900 \mathrm{e}-03$ & 1.2108 & 0.3122 & 0.9971 & 4.9184 \\
0.5 & 0.9 & 9.0 & 9.0 & $9 \mathrm{e}-03$ & $9 \mathrm{e}-03$ & $1900 \mathrm{e}-03$ & 1.4144 & 0.5171 & 0.9945 & 4.8975 \\
0.7 & 0.9 & 9.0 & 9.0 & $9 \mathrm{e}-03$ & $9 \mathrm{e}-03$ & $1900 \mathrm{e}-03$ & 1.6133 & 0.7183 & 0.9901 & 4.8683 \\
0.9 & 0.9 & 9.0 & 9.0 & $9 \mathrm{e}-03$ & $9 \mathrm{e}-03$ & $1900 \mathrm{e}-03$ & 1.8055 & 0.9142 & 0.9830 & 4.8269 \\
\hline
\end{tabular}

\section{Analysis of the results of the simulation}

The analysis of the results of the seven (7) simulations made by varying the values of the parameters of the model, one after the other, and the interpretations of the observed values of the variables $\left(v_{c 1}, v_{c 2}, i\right.$, and $\left.v_{c 3}\right)$ as related to the rate of water flow, are given below:

\section{First simulation}

An increase in the Restriction $\left(R_{1}\right)$ to flow between tanks 1 and 2 (as shown in Figure 1) (while keeping the other parameters constant, Table 4), caused reasonable increase in the water level of tank 1; water levels of tanks 2 and 3 decreased and flow $\left(i_{1}\right)$ through the filter $(L)$ also decreased, as demonstrated by the graphs shown in Figures 4, 5, 6, 7 and 8. In essence, this may be regarded as attempting to fine tune the process so as to influence the overall rate of water flow into the sachet bag (since varying $1 R$ has an effect on the water levels of tanks 1, 2, 3 and water flow $\left(i_{1}\right)$ through the filter).

\section{Second simulation}

An increase in the restriction $\left(R_{2}\right)$ of water flow between tank 2 and filter (while keeping the other parameters constant, Table 5) caused reasonable increase in water levels of tanks 1 and 2 , with tank 2 affected most, while the flow of water through the filter and the water level of tank 3 decreased. This could be interpreted to mean that an increase in $R_{2}$ decreased the water levels in tank 3 , thereby decreasing the water flow into the sachet bag. These observations are demonstrated by the graphs shown in Figures 9, 10, 11, 12 and 13. As stated above, this can also be interpreted as attempting to fine tune the process so as to influence the overall rate of water flow into the sachet bag.

\section{Third simulation}

An increase in the restriction, $\left(R_{3}\right)$ (while keeping the other parameters constant, Table 6 ) caused an increase in the water levels of all the tanks 1, 2, 3 [minimal changes (increase) in water levels of tanks 1, 2 and reasonable changes (increase) in water level of tank 3], while flow of water through the filter decreased. This observation was demonstrated by the graphs shown in Figures 14, 15, 16, 17 and 18.

The essence of this is to fine tune the process so as to get the right flow of water from the plant into the sachet bag. More specifically, this parameter is used to control the rate of water flow into the sachet bag.

\section{Fourth simulation}

Varying $L$ (the inductance) and keeping other parameters constant (Table 7), caused minimal changes (increase) in the water levels of all the tanks $1,2,3$, while the flow $\left(i_{1}\right)$ of water through the filter decreased showing that at high filtration, the flow of water through the filter lessened (decreased).

This observation is demonstrated by the graphs shown in Figures 19, 20, 21, 22 and 23. This could be interpreted as indicating that at high filtration (indicating increase in number of wound string of the conductor), the flow $\left(i_{1}\right)$ of water through the filter decreases, thereby affecting the overall output of water flow into the sachet bag.

\section{Fifth simulation}

Varying $C_{1}$ (increasing the capacity of tank 1 ) and keeping 
Table 6. Table of values with $R_{3}$ varied while other parameters were kept constant.

\begin{tabular}{ccccccccccc}
\hline$R_{3}$ & $R_{1}$ & $R_{2}$ & $L$ & $C_{1}$ & $C_{2}$ & $C_{3}$ & $v_{c 1}$ & $v_{c 2}$ & $i$ & $v_{c 3}$ \\
\hline 1.0 & 0.9 & 0.9 & 9.0 & $9 \mathrm{e}-03$ & $9 \mathrm{e}-03$ & $1900 \mathrm{e}-03$ & 1.8051 & 0.9138 & 0.9832 & 4.6573 \\
3.0 & 0.9 & 0.9 & 9.0 & $9 \mathrm{e}-03$ & $9 \mathrm{e}-03$ & $1900 \mathrm{e}-03$ & 1.8054 & 0.9141 & 0.9830 & 4.7839 \\
5.0 & 0.9 & 0.9 & 9.0 & $9 \mathrm{e}-03$ & $9 \mathrm{e}-03$ & $1900 \mathrm{e}-03$ & 1.8055 & 0.9142 & 0.9830 & 4.8096 \\
7.0 & 0.9 & 0.9 & 9.0 & $9 \mathrm{e}-03$ & $9 \mathrm{e}-03$ & $1900 \mathrm{e}-03$ & 1.8055 & 0.9142 & 0.9830 & 4.8207 \\
9.0 & 0.9 & 0.9 & 9.0 & $9 \mathrm{e}-03$ & $9 \mathrm{e}-03$ & $1900 \mathrm{e}-03$ & 1.8055 & 0.9142 & 0.9830 & 4.8269 \\
\hline
\end{tabular}

Table 7. Table of values with $L$ varied while other parameters were kept constant.

\begin{tabular}{ccccccccccc}
\hline$L$ & $R_{1}$ & $R_{2}$ & $R_{3}$ & $C_{1}$ & $C_{2}$ & $C_{3}$ & $v_{c 1}$ & $v_{c 2}$ & $i$ & $v_{c 3}$ \\
\hline 1.0 & 0.9 & 0.9 & 9.0 & $9 \mathrm{e}-03$ & $9 \mathrm{e}-03$ & $1900 \mathrm{e}-03$ & 1.7680 & 0.8714 & 0.9949 & 0.5428 \\
3.0 & 0.9 & 0.9 & 9.0 & $9 \mathrm{e}-03$ & $9 \mathrm{e}-03$ & $1900 \mathrm{e}-03$ & 1.7959 & 0.9033 & 0.9860 & 1.6138 \\
5.0 & 0.9 & 0.9 & 9.0 & $9 \mathrm{e}-03$ & $9 \mathrm{e}-03$ & $1900 \mathrm{e}-03$ & 1.8018 & 0.9099 & 0.9843 & 2.6851 \\
7.0 & 0.9 & 0.9 & 9.0 & $9 \mathrm{e}-03$ & $9 \mathrm{e}-03$ & $1900 \mathrm{e}-03$ & 1.8043 & 0.9127 & 0.9835 & 3.7562 \\
9.0 & 0.9 & 0.9 & 9.0 & $9 \mathrm{e}-03$ & $9 \mathrm{e}-03$ & $1900 \mathrm{e}-03$ & 1.8055 & 0.9142 & 0.9830 & 4.8269 \\
\hline
\end{tabular}

Table 8. Table of values with $C_{1}$ varied while other parameters were kept constant.

\begin{tabular}{ccccccccccc}
\hline$C_{1}$ & $C_{2}$ & $C_{3}$ & $L$ & $R_{1}$ & $R_{2}$ & $R_{3}$ & $v_{c 1}$ & $v_{c 2}$ & $i$ & $v_{c 3}$ \\
\hline 1e-03 & $9 \mathrm{e}-03$ & $1900 \mathrm{e}-03$ & 9.0 & 0.9 & 0.9 & 9.0 & 1.8313 & 0.9316 & 0.9960 & 4.9213 \\
3e-03 & $9 \mathrm{e}-03$ & $1900 \mathrm{e}-03$ & 9.0 & 0.9 & 0.9 & 9.0 & 1.8282 & 0.9293 & 0.9951 & 4.9085 \\
$5 \mathrm{e}-03$ & $9 \mathrm{e}-03$ & $1900 \mathrm{e}-03$ & 9.0 & 0.9 & 0.9 & 9.0 & 1.8241 & 0.9263 & 0.9933 & 4.8919 \\
$7 \mathrm{e}-03$ & $9 \mathrm{e}-03$ & $1900 \mathrm{e}-03$ & 9.0 & 0.9 & 0.9 & 9.0 & 1.8170 & 0.9215 & 0.9896 & 4.8660 \\
$9 \mathrm{e}-03$ & $9 \mathrm{e}-03$ & $1900 \mathrm{e}-03$ & 9.0 & 0.9 & 0.9 & 9.0 & 1.8055 & 0.9142 & 0.9830 & 4.8269 \\
\hline
\end{tabular}

other parameters constant (Table 8), caused changes (decrease) in all the water levels of tanks 1, 2, 3 and flow $\left(i_{1}\right)$ through the filter, as demonstrated by the graphs shown in Figures 24, 25, 26, 27 and 28.

The essence of this variation is to study the effects of $C_{1}$ (capacity of tank 1) on the process (flow of water into the sachet bag) and its interaction with the other parameters of the model. In this circumstance, the increase in the value of $C_{1}$ could be interpreted as decreasing the rate of water flow into the sachet bags.

\section{Sixth simulation}

Varying $C_{2}$ (capacity of tank 2) and keeping other parameters constant (Table 9), caused changes (decrease) in all the water levels of tanks $1,2,3$ and flow $\left(i_{1}\right)$ through the filter, as demonstrated by the graphs shown in Figures 29, 30, 31, 32 and 33.

This is also to study the effects of $C_{2}$ (capacity of tank 2) on the process (flow of water into the sachet bag) and its interaction with the other parameters of the model.

\section{Seventh simulation}

Varying $C_{3}$ (capacity of tank 3 ) and keeping other parameters constant (Table 10), caused changes (decrease) in all the water levels of tanks $1,2,3$, while it caused an increase in flow $\left(i_{1}\right)$ through the filter, showing that any variation of the capacity of tank 3 affects all the water levels of tanks 1, 2, 3 (decrease) and flow $\left(i_{1}\right)$ of water through the filter (increase). This observation is demonstrated by the graphs shown in Figures 34, 35, 36, 37 and 38. The essence of this variation is to study the effects of $C_{3}$ (capacity of tank 3 ) to the process (flow of water into the sachet bag) and its interaction with other parameters of the model.

\section{Observations}

\section{Connecting pipes}

It was observed that varying the restriction of the connecting pipes implies that either the radius (size) of the pipe is decreased/increased or the length of the pipe is increased/decreased which significantly influences the flow of 
Table 9. Table of values with $C_{2}$ varied while other parameters were kept constant.

\begin{tabular}{ccccccccccc}
\hline$C_{2}$ & $C_{1}$ & $C_{3}$ & $L$ & $R_{1}$ & $R_{2}$ & $R_{3}$ & $v_{c 1}$ & $v_{c 2}$ & $i$ & $v_{c 3}$ \\
\hline $1 \mathrm{e}-03$ & $9 \mathrm{e}-03$ & $1900 \mathrm{e}-03$ & 9.0 & 0.9 & 0.9 & 9.0 & 1.8211 & 0.9265 & 0.9935 & 4.8929 \\
$3 \mathrm{e}-03$ & $9 \mathrm{e}-03$ & $1900 \mathrm{e}-03$ & 9.0 & 0.9 & 0.9 & 9.0 & 1.8185 & 0.9243 & 0.9918 & 4.8810 \\
$5 \mathrm{e}-03$ & $9 \mathrm{e}-03$ & $1900 \mathrm{e}-03$ & 9.0 & 0.9 & 0.9 & 9.0 & 1.8143 & 0.9212 & 0.9891 & 4.8641 \\
$7 \mathrm{e}-03$ & $9 \mathrm{e}-03$ & $1900 \mathrm{e}-03$ & 9.0 & 0.9 & 0.9 & 9.0 & 1.8106 & 0.9182 & 0.9866 & 4.8479 \\
$9 \mathrm{e}-03$ & $9 \mathrm{e}-03$ & $1900 \mathrm{e}-03$ & 9.0 & 0.9 & 0.9 & 9.0 & 1.8055 & 0.9142 & 0.9830 & 4.8269 \\
\hline
\end{tabular}

Table 10. Table of values with $C_{3}$ varied while other parameters were kept constant.

\begin{tabular}{ccccccccccc}
\hline$C_{3}$ & $C_{1}$ & $C_{2}$ & $L$ & $R_{1}$ & $R_{2}$ & $R_{3}$ & $v_{c 1}$ & $v_{c 2}$ & $i$ & $v_{c 3}$ \\
\hline $1000 \mathrm{e}-03$ & $9 \mathrm{e}-03$ & $9 \mathrm{e}-03$ & 9.0 & 0.9 & 0.9 & 9.0 & 1.8287 & 0.9408 & 0.9753 & 9.4005 \\
$1300 \mathrm{e}-03$ & $9 \mathrm{e}-03$ & $9 \mathrm{e}-03$ & 9.0 & 0.9 & 0.9 & 9.0 & 1.8173 & 0.9278 & 0.9791 & 7.1447 \\
$1500 \mathrm{e}-03$ & $9 \mathrm{e}-03$ & $9 \mathrm{e}-03$ & 9.0 & 0.9 & 0.9 & 9.0 & 1.8124 & 0.9221 & 0.9807 & 6.1590 \\
$1700 \mathrm{e}-03$ & $9 \mathrm{e}-03$ & $9 \mathrm{e}-03$ & 9.0 & 0.9 & 0.9 & 9.0 & 1.8085 & 0.9177 & 0.9820 & 5.4122 \\
$1900 \mathrm{e}-03$ & $9 \mathrm{e}-03$ & $9 \mathrm{e}-03$ & 9.0 & 0.9 & 0.9 & 9.0 & 1.8055 & 0.9142 & 0.9830 & 4.8269 \\
\hline
\end{tabular}

water through the filter, but caused varying effects on the water levels in all the tanks. It is an attempt to fine tune the process so as to influence the rate of water flow (to get the right water flow from the plant).

\section{Capacity of the tanks}

It was observed that varying the value of the capacities (capacitances) of any of the tanks in the process significantly influences (decreases/increases) the water levels in all the tanks, but caused varying effects on the flow of water through the filter. This implies that an increase in the value of $C$ (capacity of tank) decreases the water level $(h)$ in the tank and hence the rate of water flow in the process, while a decrease in the value of $C$ (capacity of tank) increases $h$ and hence the rate of water flow in the process depending on the type and size of pipe used which must obey the relations stated in Equations 8-11.

\section{Inductance of the filter}

It was observed that varying the inductance $(L)$ of the filter influences the water levels in all the tanks, but caused changes (decrease) in the flow of water through the filter, implying that an increase in the inductance $(L)$ (number of wound string on the filter cartridge) increases filteration. An increase in filteration tends to decrease the flow of water through the filter, and this in turn tends to influence the rate of water flow in the process.

\section{DISCUSSION}

From these results, it was observed that by varying the electrical parameters (resistors, capacitors, inductor), it is possible to study the way the manipulation of equivalent parameters of the analogous mechanical components (the connecting pipes, the water tanks and the water filter) of the sachet water plant could influence the rate of water flow in the production process of sachet water. This work demonstrates the possibility and advantage of using electrical model to study any analogous mechanical and other system types.

\section{Conclusion}

From the analysis, it is observed that varying any of the values of the parameters of the model (Table 3 ) has an effect on the water levels in the various tanks and the flow of water through the filter. All these variations affect the overall rate of water flow into the sachet bag.

Of particular note is that varying the capacity of any of the tanks $(1,2,3)$ significantly decreases the water levels in all the tanks, but causes varying effects on the flow through the filter. The analysis of this paper on modeling a water sachet production plant is a very simple way of knowing from the beginning the various sizes of pipes, tanks and filter to be used and how these will affect the flow of water in the plant before going into the physical construction of the plant. This method could be used in a more complex system.

This paper also has shown that it is possible to use the commercially available software package, $M A T L A B^{\circledR}$, to model and simulate the dynamic behaviour of sachet water processing plant. By using the developed program, it becomes simple to 
compute and study the effect of the state variables on the system during transient state.

The program, although it is specific for sachet water processing plant, can easily be modified and adopted for any water processing plant of interest. The analysis and simulation results presented in this paper will be of immense benefit in the development and realization of a simple sachet water processing plant.

\section{REFERENCES}

Ani VA (2007). Simulation of a Sachet Water Processing Plant Using an Analogous Electrical Model. (M.Sc thesis) Department of Electronic Engineering, University of Nigeria Nsukka.

Ani VA (2007). Simulation of a Sachet Water Processing Plant Using an Analogous Electrical Model. (M.Sc thesis) Department of Electronic Engineering, University of Nigeria Nsukka.

Ani VA (2013a). Analogous Electrical Model of Water Processing Plant as a Tool to Study "The Real Problem" of Process Control. Int. J. Control Theory Comput. Model. (IJCTCM) 3:1.

Ani VA (2013b) Process Control Model of a Simple Water Treatment Plant. Trends in Mechanical Engineering and Technology (TMET)

Casey TJ (2008). Unit Treatment Processes in Water and Wastewater Engineering Aquavarra Research Limited www.aquavarra.ie/publications.

Dorf RC, Bishop RH (1998). "Modern Control Systems". AddisonWesley Longman, Inc., New York, $8^{\text {th }}$ edition, p. 38.

Hardt WF (1971). Hydrologic Analysis of Mojave River Basin, California, using Electric Analog Model. U.S. Geological Survey Open-file Report No. 97.
LeChevallier MW, Kwok-Keung AU (2004). Water Treatment and Pathogen Control: Process Efficiency in Achieving Safe Drinking Water. IWA Publishing, London, UK. http://www.who.int/water_sanitation_health/dwq/en/watreatpath6 .pdf.

MATLAB (1997). "The MATLAB Compiler User's Guide". In: Mathworks Handbook. Matheworks: Natick.

Nise SN (2003). Control Systems Engineering. John Wiley \& Sons, New York.

Ord-Smith JR, Stephenson J (1975). Computer Simulation of Continuous Systems. Cambridge University Press, London.

Patten PE (1965). Design, Construction and use of electric analog models in A.L.Wood and K.R.Gabrysch. Analog model study of ground water in the Houston District, Texas: Texas water Comm. Bull. 6508:41-60.

Perdikaris GA (1996). Computer Controlled Systems: Theory and Applications. Kluwer Academic Publishers: Netherlands.

Schwedes H (1995). Teaching with Analogies. In Psillos D. (Ed) Proceedings of the second PhD Summer School on European Research in Science Education, Thessaloniki. www.physics.ohio-state.edu/ICPE/TOC.html.

Shearer JL, Murphy AT, Richardson HH (1971). Introduction to System Dynamics. Addison-Wesley Publication Co., Inc., London, pp. 82-84, 102-165.

The Mathworks Inc (2002) Natick, MA, USA. Using MATLAB (v6.5).

Walton WC, Prickett TA (1963). Hydrogeologic Electric Analog Computer: American Society of Civil Engineers. J. Hydraul. Div. V.89, no.HY6, Proc. Paper 3695:67-91. 